\title{
Aeroelastic Optimization Study Based on the X-56A Model
}

\author{
Wesley W. $\mathrm{Li}^{1}$ and Chan-gi Pak ${ }^{2}$ \\ NASA Armstrong Flight Research Center, Edwards, CA 93523-0273
}

\begin{abstract}
One way to increase the aircraft fuel efficiency is to reduce structural weight while maintaining adequate structural airworthiness, both statically and aeroelastically. A design process which incorporates the object-oriented multidisciplinary design, analysis, and optimization (MDAO) tool and the aeroelastic effects of high fidelity finite element models to characterize the design space was successfully developed and established. This paper presents two multidisciplinary design optimization studies using an object-oriented MDAO tool developed at NASA Armstrong Flight Research Center. The first study demonstrates the use of aeroelastic tailoring concepts to minimize the structural weight while meeting the design requirements including strength, buckling, and flutter. Such an approach exploits the anisotropic capabilities of the fiber composite materials chosen for this analytical exercise with ply stacking sequence. A hybrid and discretization optimization approach improves accuracy and computational efficiency of a global optimization algorithm. The second study presents a flutter mass balancing optimization study for the fabricated flexible wing of the $\mathrm{X}-56 \mathrm{~A}$ model since a desired flutter speed band is required for the active flutter suppression demonstration during flight testing. The results of the second study provide guidance to modify the wing design and move the design flutter speeds back into the flight envelope so that the original objective of X-56A flight test can be accomplished successfully. The second case also demonstrates that the object-oriented MDAO tool can handle multiple analytical configurations in a single optimization run.
\end{abstract}

\section{Nomenclature}

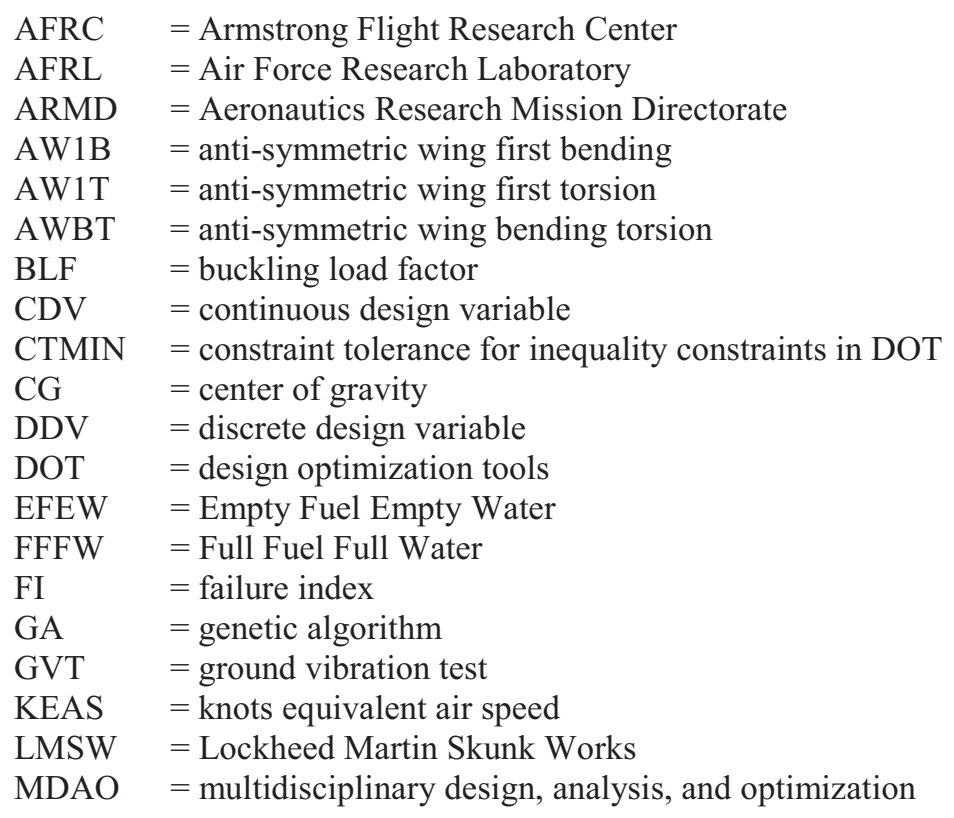

\footnotetext{
${ }^{1}$ Aerospace Engineer, Aerostructures Branch, P.O. Box 273 Edwards, California/Mailstop 48202A, Senior Member AIAA.

${ }^{2}$ Research Manager, Aerospace Engineer, Aerostructures Branch, P.O. Box 273 Edwards, California/Mailstop 48201A, Senior Member AIAA.
} 
MSC = MacNeal-Schwendler Corporation

NASA = National Aeronautics and Space Administration

SW1B = symmetric wing first bending

SW1T = symmetric wing first torsion

SBFF = symmetric body freedom flutter

SWBT = symmetric wing bending torsion

$\mathrm{V}=$ aircraft velocity

$\mathrm{V}-\mathrm{f} \quad=$ velocity-frequency

$\mathrm{V}-\mathrm{g} \quad=$ velocity-damping

$\mathrm{V}_{\mathrm{L}} \quad=$ aircraft limit speed

\section{Introduction}

$\mathrm{T}$ HE modern aircraft design of today is a multidisciplinary design procedure that requires a higher level of process integration, design innovations, and revolutionary design concepts. One of the major goals of the Fixed Wing and High Speed Projects under the National Aeronautics and Space Administration (NASA) Aeronautics Research Mission Directorate (ARMD) is the development of improved prediction methods and technologies for lower noise, lower emissions, lower sonic boom, and higher performance for subsonic, supersonic, and hypersonic aircraft. One way to increase the fuel efficiency is to reduce structural weight while maintaining adequate structural airworthiness, both statically and aeroelastically. To meet these goals, a systematic multidisciplinary design tool will support the design of a next generation aircraft. Most commercially available multidisciplinary design, analysis, and optimization (MDAO) tools, such as in MSC Nastran (MSC Software Corporation, Newport Beach, California), have been developed to perform within a limited number of disciplines with a single fidelity modeling capability and a single analytical model. Although a multitude of tools have been developed and well adapted for various disciplines in aircraft design/analysis, they have not been fully integrated to work together naturally. Data transfers between the codes are performed by using the multidisciplinary computing environment. Several works in aeroelastic optimization have been published using academic codes and/or commercial codes with high-fidelity and/or tight coupling. ${ }^{1-3}$

Over the past several years, the NASA Armstrong Flight Research Center (AFRC) (Edwards, California) has developed an object-oriented MDAO tool. ${ }^{4}$ This tool provides a computational environment in which the optimizer can effectively receive objective and constraint function values from various disciplines through the interface variables. This tool has been used to evaluate several real-world optimization problems including structural dynamic model tuning, ${ }^{5,6}$ unsteady aerodynamic model tuning, ${ }^{7}$ and mishap investigations. While the MDAO tool is a promising technology for complete vehicle system level design and optimization, ${ }^{8}$ many gaps and challenges remain to be addressed. One of the main challenges is the high computational cost of analysis which is due to the demanding nature of the high fidelity analysis in terms of model fidelity and computational resources required, as well as organizational complexity. ${ }^{9}$ As the level of fidelity is increased, the number of design variables and constraints increases. Additionally, the interdisciplinary coupling inherent in MDAO tends to present additional challenges beyond those encountered in a single-discipline optimization.

With the advanced composites materials of today, and developed optimization techniques combined, the MDAO tool has become a powerful technology allowing structures to be designed more efficiently to meet structural or aircraft performance requirements. Composite optimization with aeroelastic considerations has been a research topic for many years. ${ }^{10-13}$ Composite materials are employed to lower the structural weight due to their high strength-toweight ratio over that of metals. An overview of the earlier research provided by Vanderplaats and Weisshaar ${ }^{14}$ and Ringertz ${ }^{15}$ presents a mass minimization with aeroelastic constraints. In the past, the aeroelastic tailoring theory ${ }^{12}$ combined with the advanced composites in aircraft construction have been successfully applied to improve the performance of modern aircraft (e.g. the NASA X-29 aircraft). ${ }^{16}$

The primary objective of the aeroelastic optimization studies in this paper is to demonstrate the capability of the MDAO tool for leveraging selected engineering disciplinary codes along with the high fidelity aeroelastic analysis. A high fidelity finite element model of the X-56A aircraft was chosen for the optimization studies. This paper describes the results of two optimization studies. The first optimization study concentrates on designing a wing to avoid flutter within the flight envelope using aeroelastic tailoring concepts to minimize the structural weight while meeting the design requirements including strength, buckling, and flutter. This study is demonstrated by using a hybrid optimization technique which first uses the global optimizer to find the global optimum values and then switches to a gradient-based optimizer to accelerate the optimization procedure. The second optimization study restrains the vehicle flutter speeds within a desired range so that during flight testing engineers can examine an 
active flutter suppression system within the flight envelope. This second study also demonstrated the capability of the MDAO tool to include multiple analytical models (multi-point design) in a single optimization run. Multi-point, multi-mission optimization is considered a necessity in the aircraft design. ${ }^{17}$ This optimization study was performed using a gradient-based optimizer and was followed by sensitivity studies. Two different weight configurations were used in this study.

\section{Object-Oriented Multidisciplinary Design, Analysis and Optimization Tool}

Over the past several years, the NASA AFRC has developed an object-oriented MDAO tool. This tool is designed to handle the complex optimization problems that involve multi-point, multi-mission, multi-level analyses and multi-fidelity modeling for multi-disciplinary analyses. ${ }^{8}$ As shown in Fig. 1, each of the discipline modules is a generic system that can be easily developed, maintained, and extended. This MDAO tool leverages existing in-house codes and third party analysis tools such as Nastran, ZAERO (Zona Technology Inc., Scottsdale, Arizona) ${ }^{18}$ and a CFD solver. Users can choose an optimization methodology and provide initial design values as well as side constraints for both continuous and discrete design variables. The MDAO tool allows users easy information access, problem formulation, and execution to enable multidisciplinary optimization during the preliminary and detailed design stages of subsonic, transonic, and supersonic aircraft. Three optimization algorithms have been incorporated into the MDAO tool to include a gradient-based algorithm, a genetic algorithm (GA), ${ }^{19}$ and the big-bang big-crunch algorithm. ${ }^{20}$ In the object-Oriented MDAO Tool, design optimization tools (DOT) ${ }^{21}$ are used for the gradient-based algorithm.

The structural design of an airframe in MDAO is determined by multidisciplinary criteria which include strength, stiffness, and buckling loads for sizing optimization under given loading conditions and design requirements. Structural analysis is a complex effort involving trim analysis, loads analysis, modal analysis, and aeroelastic as well as aeroservoelastic analyses in generating output such as structural weight, deformations, divergence speed, open and closed loop flutter speeds and frequencies, natural frequencies, mode shapes, and gain/phase margins.

Several sub-modules for structural analysis disciplines have been developed and implemented in the MDAO environment. These sub-modules automate data calculation, provide data output in useful formats, and provide information to compute the objective and constraint function values. Although these sub-modules are developed mainly for MSC Nastran ${ }^{22}$ and ZAERO, they can be easily customized for other analytical tools. Some of these modules are discussed below.

1) Weight Sub-module-MSC Nastran is used to determine the model total weight, moment of inertias, and location of the center-of-gravity (CG).

2) Strength Sub-module-The material stress constraint imposed in the design process is based upon the material strength design allowable. For a feasible design, all stresses in the structure must be less than the design allowable stress of the material for all load cases. MSC Nastran was used to compute the element stress, strain, tip deflection, and composite ply failure indices. Failure theories are calculated at the ply level and the result for each element and for each ply is retrieved from the output file.

3) Buckling Sub-module-MSC Nastran is used to calculate the eigenvalue associated with the first buckling mode of the structural design with the given static load. The critical buckling load factor can also be calculated for the structure.

4) Modal Analysis Sub-module-MSC Nastran is used to determine the modal characteristics (natural frequencies and mode shapes) of the structural designs. These data are then passed on for flutter analysis with frequency constraints if needed.

5) Divergence and Flutter Sub-module-These analyses are performed using either ZONA's ZAERO code with g-method ${ }^{18}$ solution or MSC Nastran code with PK solution method ${ }^{23}$ for computing the divergence and flutter speeds. These speeds are retrieved from the output file for each configuration and flight condition. The final flutter results are displayed as velocity-damping (V-g) and velocity-frequency (V-f) plots and used to examine the flutter mechanism. The flow chart of the flutter analysis module in the MDAO tool is presented in Fig. 1.

\section{Aeroelastic Model}

The X-56A aircraft is an unmanned aircraft being developed by the U.S. Air Force Research Laboratory (AFRL) (Wright-Patterson Air Force Base, Ohio) to test technologies that will be needed for new kinds of lightweight, flexible aircraft. The 7.5 foot-long aircraft has a 28 -foot wing span and is powered by two turbine engines. The wings have an aspect ratio of 14 . The aircraft is being built and will be flown by Lockheed Martin Skunk Works ${ }^{\circledR}$ 
(LMSW) (Lockheed Martin Corporation, Bethesda, Maryland) under contract with the AFRL. After these first flight tests are completed, the valuable AFRL assets, two reusable center bodies, one stiff wing, three flex wings, and ground control stations as shown in Fig. 2, will stay at NASA AFRC for future technology demonstrations. The initial purpose of the X-56A aircraft is to demonstrate the simultaneous active suppression of three flutter mechanisms: first symmetric body-freedom flutter (SBFF), first symmetric wing bending-torsion (SWBT) flutter, and first anti-symmetric wing bending-torsion (AWBT) flutter, through the use of feedback controls. Thus, this aircraft is designed to have three flutter speeds within its flight envelope. Further details of the aircraft design can be found in reference. ${ }^{24}$

The X-56A structural model was generated using the MSC Nastran code. The structural finite element model is shown in Fig. 3. There are two straight spars and 16 straight ribs for each wing half. The wing skin, spars, and ribs are modeled using shell elements with composite material properties. The fuel and ballast weights are modeled using concentrated mass elements connected to the ribs and spars by multiple point constraint elements. The wing is connected to the center body by point spring elements. The ply orientation is defined in the local material orientation coordinate system. Positive angle direction is defined using the right-hand rule about the local z-axis.

In this study, the unsteady aerodynamics were modeled using the Doublet Lattice method ${ }^{18}$ in MSC Nastran. This model produces a matrix of linear aerodynamic influence coefficients that describe the unsteady pressure changes of the aerodynamic degrees-of-freedom. Flutter analyses is performed using the MSC Nastran PK solution method which interconnects the structural and aerodynamic grids by spline interpolation and finds the generalized aerodynamic matrix using the structural modal matrix.

\section{Description of the Optimization Problem Formulation}

The constrained optimization problem is defined as follows in Eqs. (1)-(4):

$$
\text { Find the design variables } \mathbf{X}=\left\{\begin{array}{c}
x_{1} \\
x_{2} \\
\vdots \\
x_{N}
\end{array}\right\}
$$

that minimize the objective function,

$$
f(\mathbf{X})=\text { total structural weight or flutter speeds }
$$

such that:

inequality constraints,

$$
g_{j}(\mathbf{X}) \leq 0, j=1, M
$$

equality constraints,

$$
h_{k}(\mathbf{X})=0, k=1, L
$$

and side constraints,

$$
x_{i}^{L} \leq x_{i} \leq x_{i}^{U}, \quad i=1, N
$$

where $x_{i}^{L}$ and $x_{i}^{U}$ are the lower and upper bounds on each of the design variables, respectively.

\section{A. Design Variables}

Design variables are used in the iterative design process to make changes in structural sizes, properties, and geometry. The number and type of design variables depend upon the outer shape of the aircraft as well as the geometry parameterization of the spars, ribs, upper and lower wing skin, and internal wing structure topology.

\section{B. Objective, Response, and Constraint Functions}

The response functions considered can be divided into structural and aeroelastic responses. Each of these responses can be considered as an objective or a constraint for the problem. In general, the structural responses 
include structural weight, von Mises stress and strain distributions, displacement, buckling loads factor, modal frequencies, mode shapes, et cetera. The aeroelastic responses include divergence speed, flutter speeds, and flutter frequencies. The number and type of response functions to be considered depend upon the design requirements. The behavior constraints could be equality constraints or inequality constraints, depending on the nature of the problem.

\section{Design Process and Results}

For the first optimization study, the initial baseline model originated with the LMSW X-56A aircraft with flex wings finite element model with strengthened wing upper and lower skin thicknesses. The initial model for the second optimization study was based on the GVT correlated finite element model (validated model). The structural analyses were computed by MSC Nastran codes and the response functions or performance indices were extracted from the Nastran output files. The flutter onset was computed by MSC Nastran codes, and the V-g and V-f plots were used to examine the flutter mechanism. The V-g and V-f plots indicate visually which natural vibration modes are responsible for the aeroelastic coupling. For this study, the point where the aerodynamic damping value crosses the $3 \%$ line is defined as the flutter onset point to account for an assumed structural damping. The first twenty normal modes were used to represent the structure for the flutter analysis. The flutter speed was determined at a Mach number of 0.16 .

\section{A. Study 1: Aeroelastic Tailoring}

This study concentrates on designing a wing to avoid flutter onset within the flight envelope (flutter speed greater than $1.15 \mathrm{VL}$ ) using aeroelastic tailoring concepts to minimize the structural weight while meeting the design requirements. The objective function is structural weight. Inequality constraints were used in this study, which include composite failure index (FI), buckling loads factor (BLF), flutter speeds, and flutter frequencies. The constraints and constraint tolerance values are summarized in Table 1.

A constraint is violated if its numerical value is more positive than the tolerance value. The flutter constraint tolerance for normalized inequality constraint violation was set to 0.002 . For DOT optimization, an additional constraint tolerance parameter value, CTMIN, ${ }^{14}$ of 0.003 was applied. The wing is designed to operate at $2.5 \mathrm{~g}$ and $-1.0 \mathrm{~g}$ and a factor of safety of 1.5 maneuver load conditions. These static maneuver loads are used as the applied loads for the buckling load factor calculation as well. The flutter speed requirement is that the lowest flutter speed must be greater than normalized speed of 1.62 to ensure it is flutter free within the flight envelope.

For the studies herein, a high fidelity structural model was created based on the LMSW X-56A finite element model as described in Section III. The Empty Fuel Empty Water ballast (EFEW) weight configuration was used as an initial baseline model. The outer shape of the aircraft was fixed (i.e. the aerodynamic shape did not change), and the only design variables were the ones related to the wing skin lamination parameters including ply thickness and ply orientation angles. To avoid an unrealistic thickness distribution and reduce the number of design variables in the optimization process, where each element of the finite element model is a design variable, the upper and lower skin panels were each divided into two design zones, as shown in Fig. 4. There are six design variables including three ply thickness and three ply orientation angles in each zone. The thickness and angle of plies are assumed to be constant throughout each zone. Also, design variable linking was used for the left and right wings to reduce the number of design variables and ensure symmetric design and mass distribution.

Two optimization cases, 1 and 2, with different design variable sets listed in Table 2 were investigated. The optimizations were performed with the minimization of the weight of wing composite laminates consisting of a total of 12 design variables (ply thickness only) and 24 design variables (12 ply thickness and 12 ply orientation angles) in cases 1 and 2, respectively. A hybrid optimization approach, first using a genetic algorithm (GA) to have a rough estimate of the global optimum solution and then using the DOT optimizer to accelerate the computational speed, was used in this study. In a GA, the population size depends on desired resolution and the number of design variables. In general, several hundreds or thousands of possible solutions are required to cover the entire range of possible solutions, which is very time-consuming. Therefore, first the GA optimizer with discrete design variables (DDV) was used to locate the optimum region. The GA with a population size of 200 and 30 generations with identical convergence criteria were used for cases 1 and 2. Then DOT with continuous design variables (CDV) was employed to accelerate the optimization and fine tune the optimum design. The starting design for step 2, DOT optimization, is based on the final design from step 1, GA optimization.

The structural response values and normalized flutter response values of the initial design are listed in Table 3 and Table 4 for cases 1 and 2, respectively. The normalized total weight of the initial design is set to 1.0. The starting design variable values and side constraints are listed in Table 5 and Table 6 . The skin thickness upper limit was used for all the thickness design variables to guarantee that the optimization starts from a feasible region. Cases 
1 and 2 have the same flutter mechanism, but differ slightly in flutter speed and frequency. The difference is due to the different initial ply angles. The V-g and V-f plots of the initial design are shown in Fig. 5. The SBFF, coupling of the short period mode and the symmetric wing first bending mode, were at approximately 1.69 and 1.92 for cases 1 and 2, respectively. The V-g and V-f plots also show that the coupling of the symmetric wing first bending mode and the symmetric wing first torsion mode has led to the SWBT normalized flutter speeds at approximately 2.18. Note that, AWBT normalized flutter speeds occurred at approximately 2.38 .

The optimization results of steps 1 and 2 are summarized in Table 3 and Table 4 for cases 1 and 2, respectively. As seen in the tables all of the structural response values satisfied the constraints within tolerance. The normalized final weights of cases 1 and 2, after global optimization (step 1), are 0.88 and 0.78 , respectively. The step 1 results show that case 2 , which included ply orientation angles as design variables, produce a better design weight than case 1 (i.e. additional $10 \%$ weight reduction). The additional weight saving is mainly due to the aeroelastic tailoring effect. In step 2 (DOT optimization), the optimizer is able to lower both cases of the normalized design weight further to 0.87 and 0.72 . The number of function calls for cases 1 and 2 are 1406 and 3416 in step 1, and 77 and 297 in step 2, respectively. Overall Step 2 converged much faster than the GA optimization in step 1, and it only consumed $5 \%$ to $8 \%$ of the total computational cost. The final design variable values after step 1 and step 2 for cases 1 and 2 are listed in Table 5 and Table 6.

In the airframe industry, the thickness of each type of composite ply is predefined. The final design result from DOT optimization with CDVs is not practical for manufacturing. The ply thickness has to be discretized by either rounding up or rounding down to the predefined value, and the fabric ply is placed at a 15-degree discretized angle for fabrication. Therefore, the discretization was performed after the DOT optimization. The round up and round down design variable values for cases 1 and 2 are listed in Table 5 and Table 6 . The response values based on the discretization approach are listed in Table 3 and Table 4. The results show that the round down approach for both cases leads to a violated design. The critical flutter constraint, which is the active constraint, became violated (i.e. 1.60 and 1.42 were less than the critical flutter speed requirement of about 1.62).

For the round up approach, although the critical flutter speed is satisfied for both cases with a weight penalty, other response values changed, which could be good or bad (i.e. decrease in buckling load factor response value). There is a possibility that the final design will not satisfy all the design requirements after the discretization. For case 2, Table 4 shows that the normalized final weight of the round up approach is 0.73 , which is better than the final weight, 0.78 , of the step $1 \mathrm{GA}$ optimization. The result shows that the final design from step 1 was not the best design, and the solution had not fully converged yet. With step 2, the DOT optimization plus discretization approach, a better design was found with just an additional 297 function calls which is just about $8 \%$ of the total computational cost. The aeroelastic tailoring using the hybrid and discretization optimization approach studies is summarized in Table 7. The V-g and V-f plots of the final design are shown in Fig. 6. The final design has the same flutter mechanism, and the flutter speed constraint is satisfied.

It was concluded that the hybrid and discretization optimization approach improves accuracy and computational efficiency of a global optimization algorithm. This study demonstrated that the effect of aeroelastic tailoring, which included ply orientation angles as design variables, produced an additional $10 \%$ weight reduction. A hybrid and discretization optimization approach improves accuracy and computational efficiency of a global optimization algorithm.

\section{B. Study 2: Flutter Mass Balancing}

As mentioned in Section III, the research objective of the X-56A aircraft is to demonstrate the simultaneous active suppression of three flutter mechanisms through the use of feedback controls. Thus, this aircraft is designed to have three flutter speeds within its flight envelope. The flutter speeds of the LMSW final design (non-validated model) with EFEW configuration were within the flight envelope as shown in Fig. 9. Unfortunately, after the ground vibration test (GVT) and subsequent model correlation (validated model), the second and third predicted flutter speeds of this validated model were too high or outside the flight envelope with the current propulsion systems and structural integrity. The normalized SWBT and AWBT flutter speeds at Mach 0.16 are about 1.48 and 1.68, respectively. The validated model was used as a baseline model in this flutter mass balancing study. Table 8 lists the baseline normalized flutter results at Mach 0.16 and the LMSW flutter requirements. The goal of this optimization study is to provide guidance to modify the wing design and move flutter speeds back into the flight envelope, so that the research objective can be accomplished. Since the vehicle is already fabricated, altering wing skin laminate (i.e. ply thickness and orientation angles) is not an option. Therefore, a mass balancing technique is employed. The ballast mass was modeled using concentrated mass elements in the finite element model.

The optimization approach was chosen for the mass balancing study instead of trial and error. The objective function is to minimize the total ballast weight and/or the flutter speeds while satisfying flutter speed constraints. 
Multi-points design is essential in this optimization since the total weight of the aircraft can be changed during flight. Two weight configurations, EFEW and FFFW, are taken into account in a single optimization run. The design requirements for the X-56A aircraft flutter speed and frequency constraints defined in Table 8 are used as inequality flutter constraints for the optimization. The design requirement for first flutter, SBFF, is 0.79 to 0.98 , second flutter is 0.98 to 1.18 , and third flutter is 0.98 to 1.30 . Note that the predicted normalized flutter speeds of the baseline model configurations did not meet the flutter requirements. The V-g and V-f plots of the EFEW baseline model are shown in Fig. 8(a). The normalized SBFF flutter speed for EFEW is at approximately 1.13. The plots also show that coupling of the symmetric wing first bending (SW1B) and the symmetric wing first torsion (SW1T) mode has led to the SWBT normalized flutter speeds at approximately 1.48. The AWBT normalized flutter speeds occurred at approximately 1.68 .

To move flutter speed into the flight envelope using mass balancing optimization, DOT with CDVs were used. Three design configurations and the ballast locations shown in Fig. 7 were investigated. To reduce the number of design variables and ensure symmetric design and mass distribution, design variable linking was used for left and right wings. The design variables selected in configuration 1 were six mass ballasts located primarily at the wing leading edge where each ranged up to $5 \mathrm{lb}$. For configuration 2, a total of thirteen design variables were selected, which included ten ballasts up to $5 \mathrm{lb}$ each at the wing leading and trailing edges and one single ballast up to $20 \mathrm{lb}$ at the nose of the center body. In configuration 3, the mass effectiveness was increased with a 25 -inch long aft wing tip boom and five lumped masses (ballast). The location of each ballast is defined within a five-inch segment, and each ballast can be moved with a one-inch increment. This trailing wing tip boom allows ballast to be added further behind the wing tip with a longer moment arm. The invention of the configuration 3 design was based on the optimization results of configurations 1 and 2. There were a total of eleven design variables in this configuration which included one center body nose ballast, five wing tip boom ballasts, and corresponding locations. The summary of each configuration is listed in Table 9.

The final design variables after the optimization to reduce the flutter speed of configurations 1,2 , and 3 are listed in Tables 10, 11, and 12, respectively. The flutter results are listed in Table 13. Configuration 1 optimization results show that the design variable number 6 changed from 0.0 to 5.0, which represents a 5 -lb ballast being added to the aft wing tip location. The third flutter speed was reduced from 1.68 to 1.59 and 1.67 for EFEW and FFFW cases, respectively, by the additional mass at aft wing tip. The optimization of configuration 1 and 2 has comparable results after adding $5 \mathrm{lb}$ of ballast at the aft wing tip locations to reduce the third flutter speeds. These tendencies indicated that placing the mass toward the aft wing tip increases the mass effectiveness of the ballast. These results lead to the configuration 3 design, which is the trailing wing tip boom design configuration. The configuration 2 optimization results also show that adding 20 -lb ballast at the nose of the center body can reduce the SBFF normalized speed from the configuration 1 values of 1.16 to 1.12 and 1.18 to 1.12 for EFEW and FFFW cases, respectively.

The configuration 3 design allows for the placement of the mass ballast further behind the aft wing tip to increase the mass effectiveness. Since the goal is to move the second and third flutter speeds back into the flight region, the objective function is to minimize the first flutter speed. The constraints were the second and third flutter speeds defined in Table 8. The constraints were: $0.98<\mathrm{V} 2<1.18,0.98<\mathrm{V} 3<1.3$. All the flutter frequencies were used as inequality constraints as well. Three optimizations with different initial conditions were performed as shown in Table 12. In general, all three optimization cases achieve similar results when adding about 5-lb ballast to the most aft location of the trailing wing tip boom. Case I is the most practical design out of the three. The final designs of cases I and II are lighter than case III. Furthermore the case I final design is easier to implement than case II by adding just one ballast. Case I flutter results are listed in Table 13. The results show that the second and third flutter speeds can be moved into the desired speed region by using trailing wing tip boom ballast. Notice that for the EFEW configuration, the normalized SBFF speed is 1.13 and the normalized SWBT flutter speed is 1.11. The SWBT flutter speed was reduced too much by the 5-1b weight ballast to maintain the desired order of flutter mechanisms.

As a result, a sensitivity study of the X-56A flutter characteristics using the trailing wing tip boom was performed. A 20-lb center body nose ballast was included in this study. The trailing wing tip boom tip ballast was varied from 1 to $5 \mathrm{lb}$ with $1-\mathrm{lb}$ weight increments. The flutter results are summarized in Table 14. The results indicated that to ensure the SBFF mechanism occurs before other flutter mechanisms, 3- or 4-lb instead of 5-lb ballast is recommended. With 5-lb ballast, the normalized EFEW AWBT flutter speed is 1.11 which is lower than the SBFF. The V-g and V-f plots of the EFEW model with 4-lb trailing wing tip boom ballast are shown in Fig. 8(b). The second and third predicted flutter speeds are now within the flight envelope. Based on these results, either LMSW or NASA AFRC will design and implement the trailing wing tip boom with ballast weight on the flex wing in the near future for flight testing and perform active flutter suppression with all three flutter modes in the flight envelope. The non-dimensional flight envelope of the X-56A EFEW is shown in Fig. 9, which summarized the flutter results of the LMSW final design (non-validated), the baseline (validated), and flutter mass balancing. 


\section{Conclusion}

An object-oriented MDAO tool that integrates aeroelastic effects has been developed and demonstrated. Two multidisciplinary design optimization studies were performed for the Multi Utility Technology Test-bed, X-56A aircraft. For all the sub-modules developed for this object-oriented MDAO tool, there is no restriction on the number of design variables and/or constraints as well as number of analytical configurations in a single optimization run. Although the sub-modules are developed for MSC Nastran and ZAERO, the sub-modules can be easily customized for other analytical tools.

In this paper, the first example of the aeroelastic tailoring concept which exploited the anisotropic capabilities of fiber composite materials to minimize the structural weight while maintaining desired flutter speeds has been demonstrated using the X-56A aircraft final design for further optimization. Results indicated that the objectoriented MDAO tool with high fidelity structural analysis modules can be used for preliminary and detailed design tasks of aircraft.

Results demonstrated that a genetic algorithm with discrete design variables is a beneficial approach for optimizing composite laminates with its ability to handle all types of design variables represented by realistic constraint sets in a finite element model, different material types, and manufacturing ability; thereby providing the flexibility needed to solve aeroelastic tailoring problems. Although a genetic algorithm is designed for global optimization, it is computationally inefficient and depends on the size of population and desired number of generations. In this study, a hybrid and discretization optimization approach is used to improve the computational efficiency problem with a global optimization. With the use of additional DOT optimization and discretization approaches following the genetic algorithm, the final design can be fine-tuned.

The second example of the mass balancing optimization results showed that the X-56A symmetric body freedom flutter speed can be reduced by adding nose ballast. The second and third flutter speeds can be reduced to the desired region using a trailing wing tip boom. The results of this optimization study provided guidance to modify the wing design and alter the flutter speeds back into the flight envelope, so that the original research objective of the X-56A flight test (i.e. examine an active flutter suppression system to suppress all three flutter modes) can be accomplished successfully. This example also demonstrated that the object-oriented MDAO tool can handle multiple analytical configurations in a single optimization run.

\section{Acknowledgments}

This work is supported by the AeroSciences Project under NASA ARMD Fundamental Aeronautics Program. 


\section{Tables}

Table 1. Aeroelastic tailoring optimization constraints.

\begin{tabular}{|l|c|c|l|}
\hline \multicolumn{1}{|c|}{ Constraint } & Value & $\begin{array}{c}\text { Inequality Constraint } \\
\text { Tolerance }\end{array}$ & \multicolumn{1}{c|}{ Comments } \\
\hline Composite FI 1 & $<1.0$ & 0.001 & Based on 2.5g loads. Factor of safety of 1.5. \\
\hline Composite FI 2 & $<1.0$ & 0.001 & Based on -1.0 g loads. Factor of safety of 1.5. \\
\hline Buckling load factor & $>1.0$ & 0.001 & $\begin{array}{l}\text { Applied loads are based on 2.5 g loads. Factor } \\
\text { of safety of 1.5. }\end{array}$ \\
\hline $\begin{array}{l}\text { Normalized critical Flutter } \\
\text { speed }\end{array}$ & $>1.62 *$ & 0.002 & At Mach 0.16 \\
\hline
\end{tabular}

*: Flutter speed constraint $\geq 1.62$ :

- Genetic algorithm: $\frac{1.62-V}{1.62} \leq 0.002 ; \quad V \geq 1.617$

- $\quad$ DOT: $\frac{1.62-V}{1.62} \leq(0.002+0.003)(\mathrm{CTMIN}) ; \quad V \geq 1.612$

Table 2. Aeroelastic tailoring optimization cases (Constraints: V $>1.15 V_{\mathrm{L}} ; \mathrm{BLF}>1.0$; and FI $<1.0$ ).

\begin{tabular}{|c|c|c|c|c|c|}
\hline Case & Design variable set & $\begin{array}{c}\text { Number of design } \\
\text { variables }\end{array}$ & Step & $\begin{array}{c}\text { Optimization } \\
\text { descriptions }\end{array}$ & $\begin{array}{c}\text { Number of population and } \\
\text { generation }\end{array}$ \\
\hline 1 & Thickness & 12 & 1 & GA + DDV & $200 \times 30$ \\
\cline { 3 - 6 } 2 & $\begin{array}{c}\text { Thickness }+ \\
\text { orientation }\end{array}$ & 24 & 2 & DOT + CDV & N/A \\
\cline { 3 - 5 } & & 2 & GA + DDV & DOT + CDV & N/A \\
\hline
\end{tabular}

Table 3. Aeroelastic tailoring Case 1, ply thickness optimization case non-dimensional response values.

\begin{tabular}{|c|c|c|c|c|c|c|c|c|c|c|}
\hline & \multicolumn{2}{|c|}{ Starting } & \multicolumn{2}{|c|}{$\begin{array}{c}\text { Step 1 } \\
(\mathrm{GA}+\mathrm{DDV})\end{array}$} & \multicolumn{2}{|c|}{$\begin{array}{c}\text { Step } 2 \\
(\mathrm{DOT}+\mathrm{CDV})\end{array}$} & \multicolumn{2}{|c|}{ Round down } & \multicolumn{2}{|c|}{ Round up } \\
\hline $\begin{array}{c}\text { Number of } \\
\text { function calls }\end{array}$ & \multicolumn{2}{|c|}{ N/A } & \multicolumn{2}{|c|}{1406} & \multicolumn{2}{|c|}{77} & \multicolumn{2}{|c|}{$\mathrm{N} / \mathrm{A}$} & \multicolumn{2}{|c|}{$\mathrm{N} / \mathrm{A}$} \\
\hline $\begin{array}{c}\text { Normalized } \\
\text { weight } \\
\text { reduction }\end{array}$ & \multicolumn{2}{|c|}{1.0} & \multicolumn{2}{|c|}{0.88} & \multicolumn{2}{|c|}{0.87} & \multicolumn{2}{|c|}{0.86} & \multicolumn{2}{|c|}{0.89} \\
\hline Composite FI 1 & \multicolumn{2}{|c|}{0.26} & \multicolumn{2}{|c|}{0.28} & \multicolumn{2}{|c|}{0.30} & \multicolumn{2}{|c|}{0.30} & \multicolumn{2}{|c|}{0.29} \\
\hline Composite FI 2 & \multicolumn{2}{|c|}{0.17} & \multicolumn{2}{|c|}{0.19} & \multicolumn{2}{|c|}{0.20} & \multicolumn{2}{|c|}{0.20} & \multicolumn{2}{|c|}{0.20} \\
\hline $\begin{array}{c}\text { Buckling load } \\
\text { factor }\end{array}$ & \multicolumn{2}{|c|}{1.05} & \multicolumn{2}{|c|}{1.14} & \multicolumn{2}{|c|}{1.16} & \multicolumn{2}{|c|}{1.18} & \multicolumn{2}{|c|}{1.14} \\
\hline \multirow{2}{*}{$\begin{array}{l}\text { Normalized } \\
\text { critical flutter }\end{array}$} & Speed & Freq. & Speed & Freq. & Speed & Freq. & Speed & Freq. & Speed & Freq. \\
\hline & 1.69 & 0.97 & 1.62 & 0.97 & 1.61 & 0.96 & 1.60 & 0.96 & 1.64 & 0.97 \\
\hline
\end{tabular}


Table 4. Aeroelastic tailoring Case 2, ply thickness and orientation case non-dimensional response values.

\begin{tabular}{|c|c|c|c|c|c|c|c|c|c|c|}
\hline & \multicolumn{2}{|c|}{ Starting } & \multicolumn{2}{|c|}{$\begin{array}{c}\text { Step 1 } \\
\text { (GA +DDV) }\end{array}$} & \multicolumn{2}{|c|}{$\begin{array}{c}\text { Step } 2 \\
(\mathrm{DOT}+\mathrm{CDV})\end{array}$} & \multicolumn{2}{|c|}{ Round down } & \multicolumn{2}{|c|}{ Round up } \\
\hline $\begin{array}{l}\text { Number of } \\
\text { function calls }\end{array}$ & \multicolumn{2}{|c|}{ N/A } & \multicolumn{2}{|c|}{3416} & \multicolumn{2}{|c|}{297} & \multicolumn{2}{|c|}{ N/A } & \multicolumn{2}{|c|}{ N/A } \\
\hline $\begin{array}{c}\text { Normalized } \\
\text { weight } \\
\text { reduction }\end{array}$ & \multicolumn{2}{|c|}{1.0} & \multicolumn{2}{|c|}{0.78} & \multicolumn{2}{|c|}{0.72} & \multicolumn{2}{|c|}{0.70} & \multicolumn{2}{|c|}{0.73} \\
\hline Composite FI 1 & \multicolumn{2}{|c|}{0.26} & \multicolumn{2}{|c|}{0.43} & \multicolumn{2}{|c|}{0.40} & \multicolumn{2}{|c|}{0.43} & \multicolumn{2}{|c|}{0.39} \\
\hline Composite FI 2 & \multicolumn{2}{|c|}{0.087} & \multicolumn{2}{|c|}{0.28} & \multicolumn{2}{|c|}{0.27} & \multicolumn{2}{|c|}{0.27} & \multicolumn{2}{|c|}{0.26} \\
\hline $\begin{array}{l}\text { Buckling load } \\
\text { factor }\end{array}$ & \multicolumn{2}{|c|}{1.05} & \multicolumn{2}{|c|}{1.24} & \multicolumn{2}{|c|}{1.26} & \multicolumn{2}{|c|}{1.27} & \multicolumn{2}{|c|}{1.25} \\
\hline \multirow{2}{*}{$\begin{array}{l}\text { Normalized } \\
\text { critical flutter }\end{array}$} & Speed & Freq. & Speed & Freq. & Speed & Freq. & Speed & Freq. & Speed & Freq. \\
\hline & 1.92 & 0.83 & 1.62 & 0.57 & 1.61 & 0.56 & 1.42 & 0.64 & 1.62 & 0.63 \\
\hline
\end{tabular}

Table 5. Aeroelastic tailoring Case 1, ply thickness case design variable values (inch).

\begin{tabular}{|c|c|c|c|c|c|c|c|}
\hline $\begin{array}{c}\text { Design } \\
\text { variables }\end{array}$ & Lower limit & Starting & After step 1 & After step 2 & $\begin{array}{c}\text { Round } \\
\text { down }\end{array}$ & Round up & Upper limit \\
\hline 1 & 0.0101 & 0.1010 & 0.0909 & 0.0864 & 0.0808 & 0.0909 & 0.1010 \\
\hline 2 & 0.0101 & 0.1010 & 0.1010 & 0.0945 & 0.0909 & 0.1010 & 0.1010 \\
\hline 3 & 0.0625 & 0.6250 & 0.1250 & 0.0625 & 0.0625 & 0.0625 & 0.6250 \\
\hline 4 & 0.0101 & 0.1010 & 0.0707 & 0.0537 & 0.0505 & 0.0606 & 0.1010 \\
\hline 5 & 0.0101 & 0.1010 & 0.0101 & 0.0135 & 0.0101 & 0.0202 & 0.1010 \\
\hline 6 & 0.0101 & 0.1010 & 0.0808 & 0.0630 & 0.0606 & 0.0707 & 0.1010 \\
\hline 7 & 0.0101 & 0.1010 & 0.0909 & 0.1010 & 0.1010 & 0.1010 & 0.1010 \\
\hline 8 & 0.0101 & 0.1010 & 0.0808 & 0.1010 & 0.1010 & 0.1010 & 0.1010 \\
\hline 9 & 0.0625 & 0.6250 & 0.6250 & 0.6250 & 0.6250 & 0.6250 & 0.6250 \\
\hline 10 & 0.0101 & 0.1010 & 0.0606 & 0.0510 & 0.0505 & 0.0606 & 0.1010 \\
\hline 11 & 0.0101 & 0.1010 & 0.0404 & 0.0321 & 0.0303 & 0.0404 & 0.1010 \\
\hline 12 & 0.0101 & 0.1010 & 0.0707 & 0.0606 & 0.0606 & 0.0606 & 0.1010 \\
\hline
\end{tabular}


Table 6. Aeroelastic tailoring Case 2, ply thickness and orientation case design variable values (thickness $=$ inch and angle $=$ degree).

\begin{tabular}{|c|c|c|c|c|c|c|c|}
\hline $\begin{array}{c}\text { Design } \\
\text { variables }\end{array}$ & Lower limit & Starting & After step 1 & After step 2 & Round down & Round up & Upper limit \\
\hline 1 & 0.0101 & 0.1010 & 0.0606 & 0.0349 & 0.0303 & 0.0404 & 0.1010 \\
\hline 2 & 0.0101 & 0.1010 & 0.0808 & 0.0567 & 0.0505 & 0.0606 & 0.1010 \\
\hline 3 & 0.0625 & 0.6250 & 0.4375 & 0.5177 & 0.5000 & 0.5625 & 0.6250 \\
\hline 4 & -45.00 & 45.00 & -45.00 & -45.00 & -45.00 & -45.00 & 90.00 \\
\hline 5 & -45.00 & 90.00 & -45.00 & -45.00 & -45.00 & -45.00 & 90.00 \\
\hline 6 & -45.00 & 45.00 & 30.00 & 31.84 & 30.00 & 30.00 & 90.00 \\
\hline 7 & 0.0101 & 0.1010 & 0.0505 & 0.0167 & 0.0101 & 0.0202 & 0.1010 \\
\hline 8 & 0.0101 & 0.1010 & 0.0101 & 0.0101 & 0.0101 & 0.0101 & 0.1010 \\
\hline 9 & 0.0101 & 0.1010 & 0.0101 & 0.0101 & 0.0101 & 0.0101 & 0.1010 \\
\hline 10 & -45.00 & 45.00 & 15.00 & 36.31 & 30.00 & 30.00 & 90.00 \\
\hline 11 & -45.00 & 90.00 & 0.00 & -19.39 & -15.00 & -15.00 & 90.00 \\
\hline 12 & -45.00 & 45.00 & 90.00 & 43.13 & 45.00 & 45.00 & 90.00 \\
\hline 13 & 0.0101 & 0.1010 & 0.0101 & 0.0101 & 0.0101 & 0.0101 & 0.1010 \\
\hline 14 & 0.0101 & 0.1010 & 0.0808 & 0.0803 & 0.0707 & 0.0808 & 0.1010 \\
\hline 15 & 0.0625 & 0.6250 & 0.5000 & 0.4907 & 0.4375 & 0.5000 & 0.6250 \\
\hline 16 & -45.00 & 45.00 & 90.00 & 72.89 & 75.00 & 75.00 & 90.00 \\
\hline 17 & -45.00 & 90.00 & -45.00 & -45.00 & -45.00 & -45.00 & 90.00 \\
\hline 18 & -45.00 & 45.00 & 75.00 & 73.76 & 75.00 & 75.00 & 90.00 \\
\hline 19 & 0.0101 & 0.1010 & 0.0101 & 0.0198 & 0.0101 & 0.0202 & 0.1010 \\
\hline 20 & 0.0101 & 0.1010 & 0.0303 & 0.0181 & 0.0101 & 0.0202 & 0.1010 \\
\hline 21 & 0.0101 & 0.1010 & 0.0606 & 0.0264 & 0.0202 & 0.0303 & 0.1010 \\
\hline 22 & -45.00 & 45.00 & -30.00 & -45.00 & -45.00 & -45.00 & 90.00 \\
\hline 23 & -45.00 & 90.00 & 60.00 & 44.03 & 45.00 & 45.00 & 90.00 \\
\hline 24 & -45.00 & 45.00 & -30.00 & -45.00 & -45.00 & -45.00 & 90.00 \\
\hline & & & & & & & \\
\hline
\end{tabular}

Table 7. Summary of the aeroelastic tailoring optimization study.

\begin{tabular}{|c|c|c|c|c|c|c|c|c|}
\hline & \multicolumn{4}{|c|}{ Case 1, ply thickness } & \multicolumn{4}{|c|}{ Case 2, ply thickness and orientation } \\
\hline & \multicolumn{2}{|c|}{$\begin{array}{c}\text { Step 1 } \\
(\mathrm{GA}+\mathrm{DDV})\end{array}$} & \multicolumn{2}{|c|}{$\begin{array}{l}\text { After step } 2 \\
\text { round up }\end{array}$} & \multicolumn{2}{|c|}{$\begin{array}{c}\text { Step 1 } \\
\text { (GA +DDV) }\end{array}$} & \multicolumn{2}{|c|}{$\begin{array}{l}\text { After step } 2 \\
\text { round up }\end{array}$} \\
\hline $\begin{array}{l}\text { Number of } \\
\text { function calls }\end{array}$ & \multicolumn{2}{|c|}{1406} & \multicolumn{2}{|c|}{77} & \multicolumn{2}{|c|}{$3416^{*}$} & \multicolumn{2}{|c|}{$297 *$} \\
\hline $\begin{array}{c}\text { Normalized } \\
\text { weight reduction }\end{array}$ & \multicolumn{2}{|c|}{$0.88 * *$} & \multicolumn{2}{|c|}{0.89} & \multicolumn{2}{|c|}{$0.78 * *$} & \multicolumn{2}{|c|}{0.73} \\
\hline Composite FI 1 & \multicolumn{2}{|c|}{0.28} & \multicolumn{2}{|c|}{0.29} & \multicolumn{2}{|c|}{0.43} & \multicolumn{2}{|c|}{0.39} \\
\hline Composite FI 2 & \multicolumn{2}{|c|}{0.19} & \multicolumn{2}{|c|}{0.20} & \multicolumn{2}{|c|}{0.28} & \multicolumn{2}{|c|}{0.26} \\
\hline $\begin{array}{l}\text { Buckling load } \\
\text { factor }\end{array}$ & \multicolumn{2}{|c|}{1.14} & \multicolumn{2}{|c|}{1.14} & \multicolumn{2}{|c|}{1.24} & \multicolumn{2}{|c|}{1.25} \\
\hline \multirow{2}{*}{$\begin{array}{l}\text { Normalized } \\
\text { critical flutter }\end{array}$} & Speed & Freq. & Speed & Freq. & Speed & Freq. & Speed & Freq. \\
\hline & 1.62 & 0.97 & 1.64 & 0.97 & 1.62 & 0.57 & 1.62 & 0.63 \\
\hline
\end{tabular}

*: Effect of hybrid optimization + discretization: accelerate global optimizer; further improve design with about $8 \%$ of additional function calls

**: Effect of aeroelastic tailoring: 0.88 vs. 0.78 (10\% more reduction by aeroelastic tailoring) 
Table 8. Mass balancing baseline flutter predictions and requirements at Mach 0.16.

\begin{tabular}{|c|c|c|c|c|c|c|c|c|}
\hline \multirow{2}{*}{$\begin{array}{c}\text { Flutter } \\
\text { mode }\end{array}$} & \multicolumn{4}{|c|}{ Normalized speed } & \multicolumn{4}{c|}{ Normalized frequency } \\
\cline { 2 - 9 } & $\begin{array}{c}\text { Lower } \\
\text { bound } \\
\text { requirement }\end{array}$ & EFEW* & FFFW* & $\begin{array}{c}\text { Upper } \\
\text { bound } \\
\text { requirement }\end{array}$ & $\begin{array}{c}\text { Lower } \\
\text { bound } \\
\text { requirement }\end{array}$ & EFEW & FFFW & $\begin{array}{c}\text { Upper } \\
\text { bound } \\
\text { requirement }\end{array}$ \\
\hline SBFF & 0.79 & 1.13 & 1.16 & 0.98 & 0.53 & 0.68 & 0.53 & 1.76 \\
\hline SWBT & 0.98 & 1.48 & 1.48 & 1.18 & 1.17 & 2.34 & 2.25 & 2.35 \\
\hline AWBT & 0.98 & 1.68 & 1.68 & 1.30 & 1.50 & 1.52 & 2.43 & 3.52 \\
\hline
\end{tabular}

*: Flutter speed is beyond upper bound requirement

Table 9. Flutter mass balancing design configurations descriptions.

\begin{tabular}{|c|c|c|c|c|c|c|c|}
\hline \multirow{2}{*}{ Configuration } & \multirow{2}{*}{$\begin{array}{l}\text { Number } \\
\text { of design } \\
\text { variables }\end{array}$} & \multirow{2}{*}{ Objective } & \multicolumn{4}{|c|}{ Side constraints } & \multirow{2}{*}{ Comments } \\
\cline { 3 - 6 } & & $\begin{array}{c}\text { Nose ballast (lb) } \\
\text { Lower } \\
\text { limit }\end{array}$ & $\begin{array}{c}\text { Upper } \\
\text { limit }\end{array}$ & $\begin{array}{c}\text { Lower } \\
\text { limit }\end{array}$ & $\begin{array}{c}\text { Upper } \\
\text { limit }\end{array}$ & \\
\hline & 6 & $\begin{array}{l}\text { Min. total } \\
\text { ballast weight } \\
\text { and target } \\
\text { flutter speed }\end{array}$ & N/A & N/A & 0.0 & 5.0 & $\begin{array}{l}\text { Wing leading edge } \\
\text { optimization: 5 wing leading } \\
\text { edge and 1 aft wing tip }\end{array}$ \\
\hline 2 & 13 & $\begin{array}{l}\text { Min. total } \\
\text { ballast weight } \\
\text { and target } \\
\text { flutter speed }\end{array}$ & 0.0 & 20.0 & 0.0 & 5.0 & $\begin{array}{l}\text { Wing leading and trailing } \\
\text { edge optimization: 1 nose, } 6 \\
\text { wing leading edge and 6 wing } \\
\text { trailing edge locations }\end{array}$ \\
\hline 3 & 11 & $\begin{array}{l}\text { Min. the first } \\
\text { flutter speed. }\end{array}$ & 0.0 & 20.0 & 0.0 & 5.0 & $\begin{array}{l}\text { Aft wing tip boom } \\
\text { optimization: 1 nose, 5 wing } \\
\text { tip boom ballast and 5 wing } \\
\text { tip ballast locations }\end{array}$ \\
\hline
\end{tabular}

Table 10. Flutter mass balancing configuration 1 design variables.

\begin{tabular}{|c|c|c|c|c|}
\hline \multicolumn{5}{|c|}{ Configuration 1} \\
\hline \multirow{2}{*}{ Design variable } & \multirow{2}{*}{ Initial value } & \multirow{2}{*}{ Final value } & \multicolumn{2}{|c|}{ Side constraints } \\
\hline & & & Lower limit & Upper limit \\
\hline \multicolumn{5}{|c|}{ Wing leading edge ballast (lb) } \\
\hline 1 & 0.0 & 0.0 & 0.0 & 5.0 \\
\hline 2 & 0.0 & 0.0 & 0.0 & 5.0 \\
\hline 3 & 0.0 & 0.0 & 0.0 & 5.0 \\
\hline 4 & 0.0 & 0.0 & 0.0 & 5.0 \\
\hline 5 & 0.0 & 0.0 & 0.0 & 5.0 \\
\hline \multicolumn{5}{|c|}{ Wing trailing edge ballast (lb) } \\
\hline 6 & 0.0 & 5.0 & 0.0 & 5.0 \\
\hline
\end{tabular}


Table 11. Flutter mass balancing configuration 2 design variables.

\begin{tabular}{|c|c|c|c|c|}
\hline \multicolumn{5}{|c|}{ Configuration 2} \\
\hline \multirow{2}{*}{ Design variable } & \multirow{2}{*}{ Initial value } & \multirow{2}{*}{ Final value } & \multicolumn{2}{|c|}{ Side constraints } \\
\hline & & & Lower limit & Upper limit \\
\hline \multicolumn{5}{|c|}{ Nose ballast (lb) } \\
\hline 1 & 0.0 & 20.0 & 0.0 & 20.0 \\
\hline \multicolumn{5}{|c|}{ Wing leading edge ballast (lb) } \\
\hline 2 & 0.0 & 0.0 & 0.0 & 5.0 \\
\hline 3 & 0.0 & 0.0 & 0.0 & 5.0 \\
\hline 4 & 0.0 & 0.0 & 0.0 & 5.0 \\
\hline 5 & 0.0 & 0.0 & 0.0 & 5.0 \\
\hline 6 & 0.0 & 0.0 & 0.0 & 5.0 \\
\hline 7 & 0.0 & 0.0 & 0.0 & 5.0 \\
\hline \multicolumn{5}{|c|}{ Wing trailing edge ballast (lb) } \\
\hline 8 & 0.0 & 0.0 & 0.0 & 5.0 \\
\hline 9 & 0.0 & 0.0 & 0.0 & 5.0 \\
\hline 10 & 0.0 & 0.0 & 0.0 & 5.0 \\
\hline 11 & 0.0 & 0.0 & 0.0 & 5.0 \\
\hline 12 & 0.0 & 0.0 & 0.0 & 5.0 \\
\hline 13 & 0.0 & 5.0 & 0.0 & 5.0 \\
\hline
\end{tabular}

Table 12. Flutter mass balancing configuration 3 design variables.

\begin{tabular}{|c|c|c|c|c|c|c|c|c|}
\hline \multicolumn{9}{|c|}{ Configuration 3} \\
\hline \multirow[b]{2}{*}{$\begin{array}{c}\text { Design } \\
\text { variable }\end{array}$} & \multicolumn{2}{|c|}{ Case I } & \multicolumn{2}{|c|}{ Case II } & \multicolumn{2}{|c|}{ Case III } & \multicolumn{2}{|c|}{ Side constraints } \\
\hline & $\begin{array}{l}\text { Initial } \\
\text { value }\end{array}$ & $\begin{array}{l}\text { Final } \\
\text { value }\end{array}$ & $\begin{array}{l}\text { Initial } \\
\text { value }\end{array}$ & $\begin{array}{l}\text { Final } \\
\text { value }\end{array}$ & $\begin{array}{l}\text { Initial } \\
\text { value }\end{array}$ & $\begin{array}{l}\text { Final } \\
\text { value }\end{array}$ & $\begin{array}{c}\text { Lower } \\
\text { limit }\end{array}$ & $\begin{array}{l}\text { Upper } \\
\text { limit }\end{array}$ \\
\hline \multicolumn{9}{|c|}{ Nose ballast (lb) } \\
\hline 1 & 20.0 & 20.0 & 20.0 & 20.0 & 20.0 & 20.0 & 0.0 & 20.0 \\
\hline \multicolumn{9}{|c|}{ Wing tip boom ballast (lb) } \\
\hline 2 & 0.0 & 0.0 & 0.0 & 0.0 & 1.0 & 0.0 & 0.0 & 5.0 \\
\hline 3 & 0.0 & 0.0 & 4.8 & 0.0 & 1.0 & 0.04 & 0.0 & 5.0 \\
\hline 4 & 0.0 & 0.0 & 0.0 & 0.0 & 1.0 & 0.04 & 0.0 & 5.0 \\
\hline 5 & 0.0 & 0.0 & 0.0 & 0.3 & 1.0 & 2.4 & 0.0 & 5.0 \\
\hline 6 & 0.0 & 5.0 & 0.0 & 4.7 & 1.0 & 5.0 & 0.0 & 5.0 \\
\hline \multicolumn{9}{|c|}{ Wing tip ballast $\mathrm{x}$ location (inch) } \\
\hline 7 & 216 & 216 & 216 & 216 & 216 & 216 & 211 & 216 \\
\hline 8 & 221 & 221 & 221 & 221 & 221 & 221 & 216 & 221 \\
\hline 9 & 226 & 226 & 226 & 226 & 226 & 226 & 221 & 226 \\
\hline 10 & 231 & 231 & 231 & 231 & 231 & 231 & 226 & 231 \\
\hline 11 & 236 & 236 & 236 & 236 & 236 & 236 & 231 & 236 \\
\hline
\end{tabular}


Table 13. Flutter mass balancing flutter results.

\begin{tabular}{|c|c|c|c|c|c|c|c|c|c|c|}
\hline \multicolumn{11}{|c|}{ Normalized flutter speeds } \\
\hline \multirow{3}{*}{ Flutter mode } & \multicolumn{10}{|c|}{$\begin{array}{l}\text { Configuration } \\
\end{array}$} \\
\hline & \multicolumn{2}{|c|}{1} & \multicolumn{2}{|c|}{2} & \multicolumn{2}{|c|}{3 - case I } & \multicolumn{2}{|c|}{3 - case II } & \multicolumn{2}{|c|}{3 - case III } \\
\hline & EFEW & FFFW & EFEW & FFFW & EFEW & FFFW & EFEW & FFFW & EFEW & FFFW \\
\hline SBFF & 1.16 & 1.18 & 1.12 & 1.12 & 1.13 & 1.14 & 1.13 & 1.14 & 1.14 & 1.14 \\
\hline SWBT & 1.49 & 1.67 & 1.49 & 1.67 & $1.11^{*}$ & 1.18 & $1.12 *$ & 1.18 & $1.06^{*}$ & $1.10^{*}$ \\
\hline AWBT & 1.59 & 1.57 & 1.56 & 1.55 & 1.29 & 1.26 & 1.29 & 1.26 & 1.30 & 1.26 \\
\hline \multicolumn{11}{|c|}{ Normalized flutter frequency } \\
\hline \multirow{3}{*}{ Flutter mode } & \multicolumn{10}{|c|}{ Configuration } \\
\hline & \multicolumn{2}{|c|}{1} & \multicolumn{2}{|c|}{2} & \multicolumn{2}{|c|}{3 - case I } & \multicolumn{2}{|c|}{3 - case II } & \multicolumn{2}{|c|}{3 - case III } \\
\hline & EFEW & FFFW & EFEW & FFFW & EFEW & FFFW & EFEW & FFFW & EFEW & FFFW \\
\hline SBFF & 0.66 & 0.52 & 0.71 & 0.58 & 0.72 & 0.58 & 0.72 & 0.58 & 0.71 & 0.57 \\
\hline SWBT & 1.28 & 1.25 & 1.28 & 1.25 & 1.07 & 1.03 & 1.07 & 1.03 & 0.99 & 0.95 \\
\hline AWBT & 2.09 & 2.02 & 2.07 & 2.01 & 1.57 & 1.55 & 1.57 & 1.54 & 1.44 & 1.42 \\
\hline
\end{tabular}

*: Flutter happens before SBFF.

Table 14. Wing tip boom flutter mass balancing sensitivity study flutter results (Note: includes $20 \mathrm{lb}$ center body nose ballast).

\begin{tabular}{|c|c|c|c|c|c|}
\hline \multirow[b]{2}{*}{$\begin{array}{c}\text { Wing tip boom ballast } \\
\text { weight (lb) }\end{array}$} & \multicolumn{2}{|c|}{ FFFW } & \multicolumn{2}{|c|}{ EFEW } & \multirow[b]{2}{*}{ Flutter descriptions } \\
\hline & $\begin{array}{c}\text { Normalized } \\
\text { speed }\end{array}$ & $\begin{array}{l}\text { Normalized } \\
\text { frequency }\end{array}$ & $\begin{array}{c}\text { Normalized } \\
\text { speed }\end{array}$ & $\begin{array}{l}\text { Normalized } \\
\text { frequency }\end{array}$ & \\
\hline \multirow{3}{*}{1} & 1.12 & 0.59 & 1.11 & 0.73 & SBFF \\
\hline & 1.37 & 1.96 & 1.38 & 2.02 & AWBT \\
\hline & 1.60 & 1.29 & 1.39 & 1.30 & SWBT \\
\hline \multirow{3}{*}{2} & 1.13 & 0.59 & 1.12 & 0.73 & SBFF \\
\hline & 1.32 & 1.82 & 1.34 & 1.87 & AWBT \\
\hline & 1.43 & 1.19 & 1.28 & 1.23 & SWBT \\
\hline \multirow{3}{*}{3} & 1.13 & 0.58 & 1.12 & 0.72 & SBFF \\
\hline & 1.29 & 1.71 & 1.31 & 1.75 & AWBT \\
\hline & 1.32 & 1.12 & 1.21 & 1.17 & SWBT \\
\hline \multirow{3}{*}{4} & 1.13 & 0.58 & 1.12 & 0.72 & SBFF \\
\hline & 1.28 & 1.62 & 1.25 & 1.66 & AWBT \\
\hline & 1.24 & 1.07 & 1.30 & 1.12 & SWBT \\
\hline \multirow{3}{*}{5} & 1.14 & 0.58 & 1.13 & 0.72 & SBFF \\
\hline & 1.26 & 1.54 & 1.11 & 1.57 & AWBT \\
\hline & 1.18 & 1.03 & $\overline{1.29}$ & 1.07 & SWBT \\
\hline
\end{tabular}


Figures

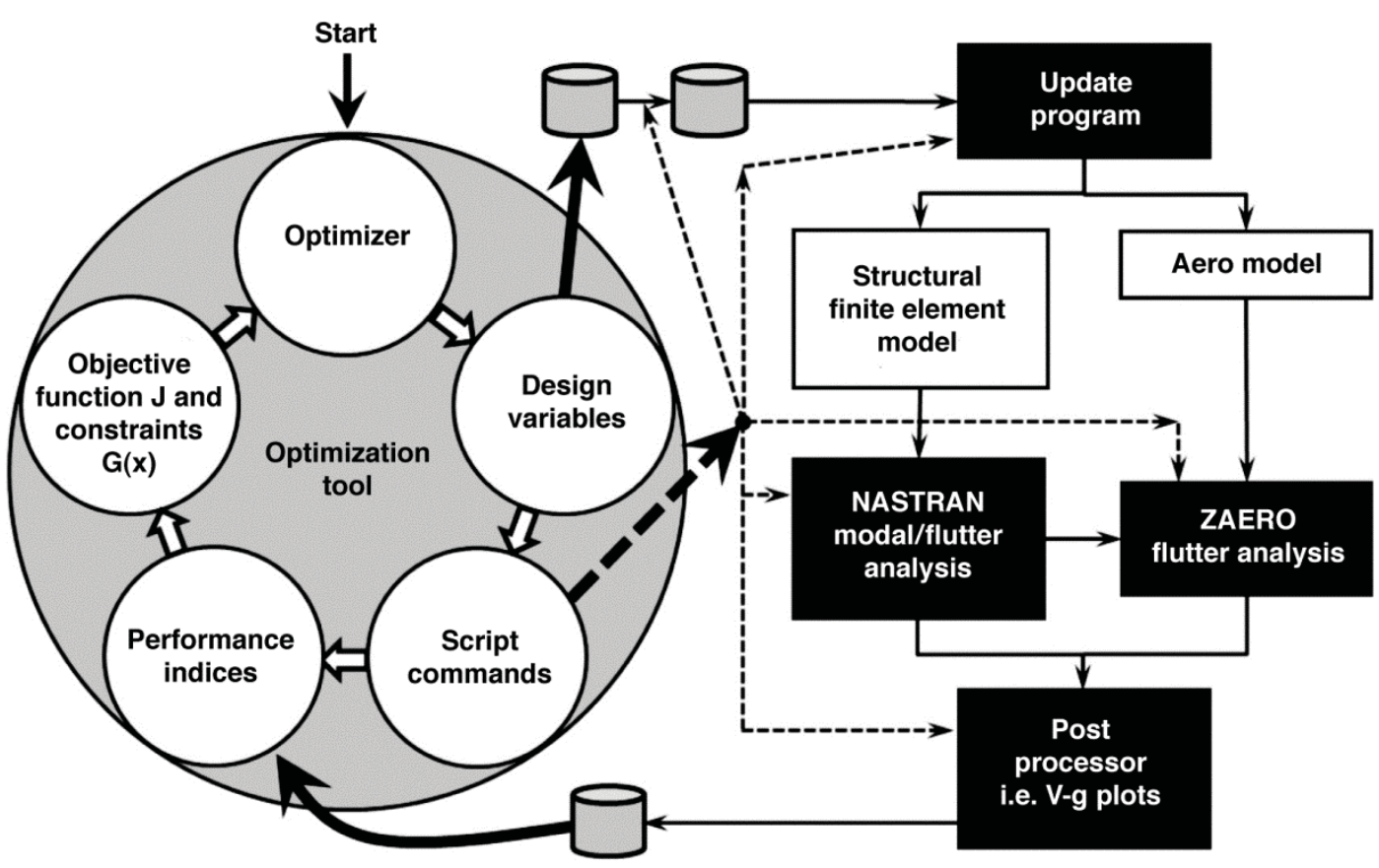

Figure 1. Flowchart of the flutter analysis module in the object-oriented MDAO tool.

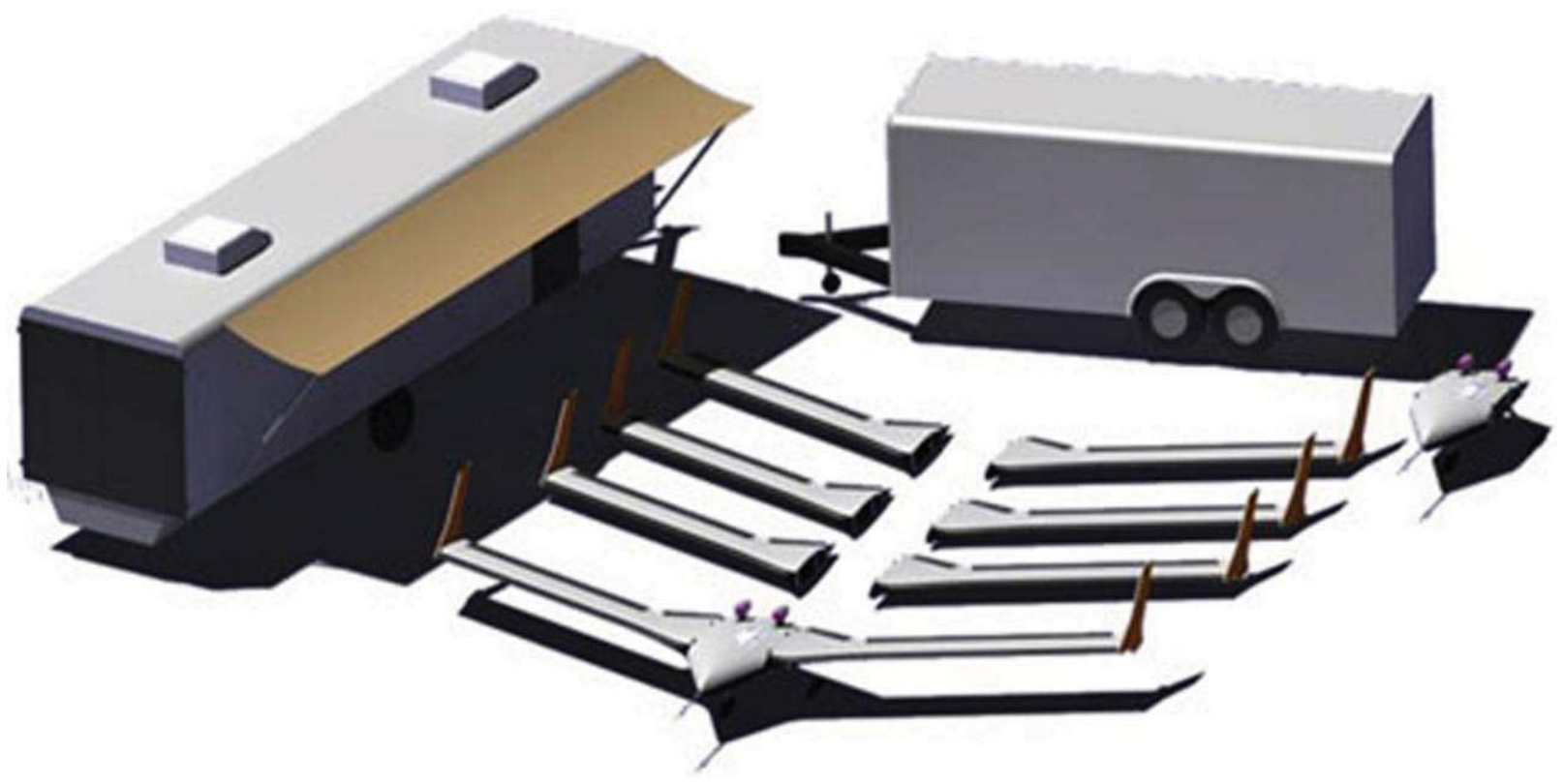

Figure 2. Lockheed Martin Corporation X-56A aircraft (Figure courtesy: AFRL/Lockheed Martin). 


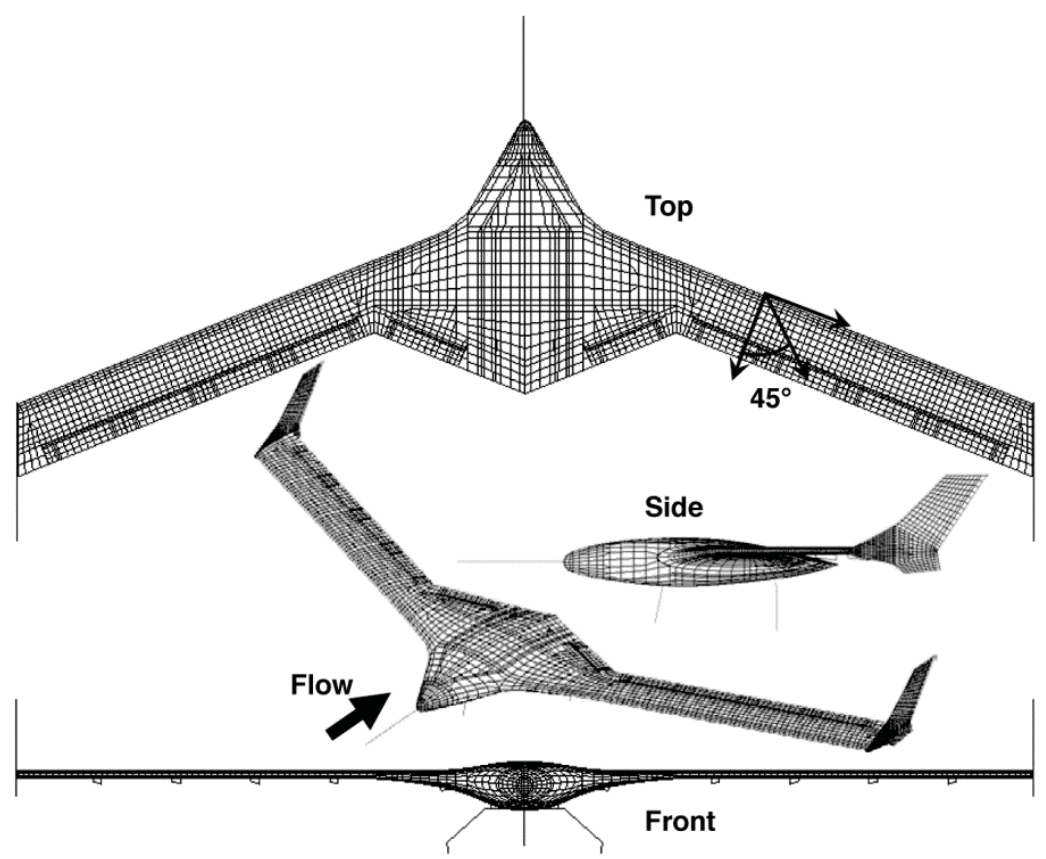

Figure 3. X-56A baseline structural finite element model.

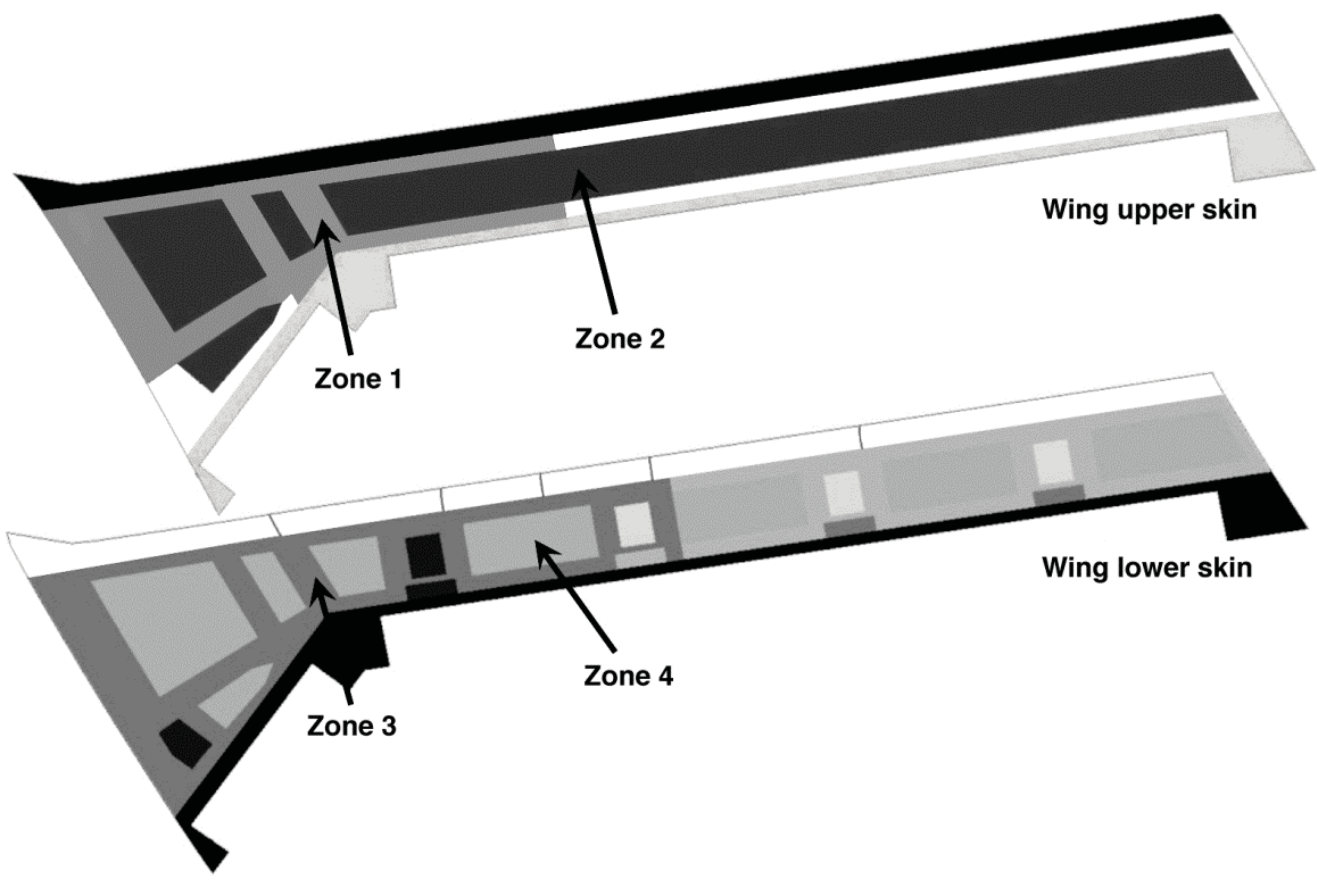

Figure 4. X-56A baseline wing upper and lower skin design variable map. 
a)
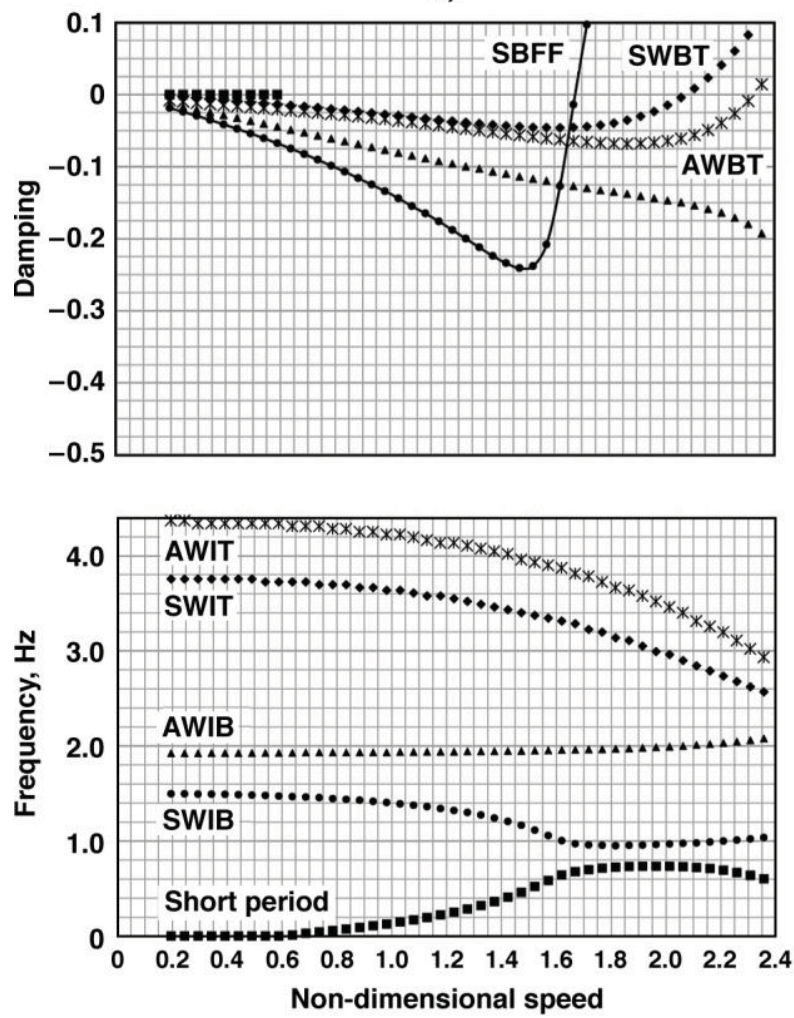

b)
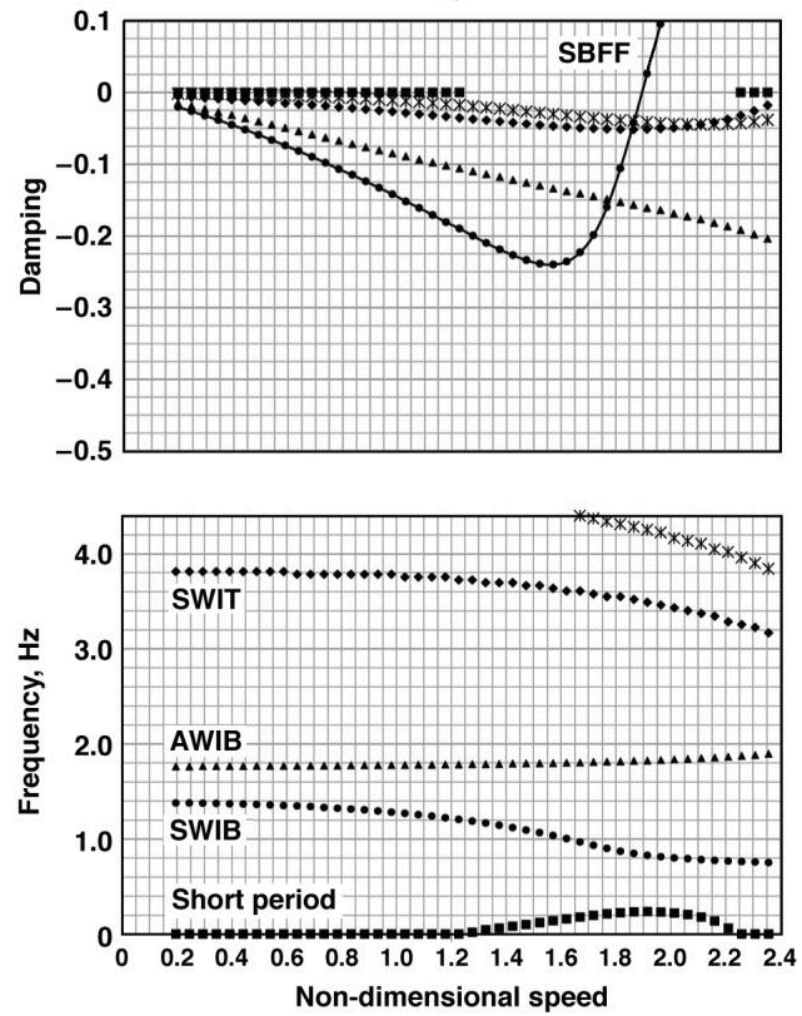

Figure 5. The V-g and V-f plots for aeroelastic tailoring optimization initial design: (a) Case 1: ply thickness design variables case; (b) Case 2: ply thickness and orientation design variables cases. 
a)
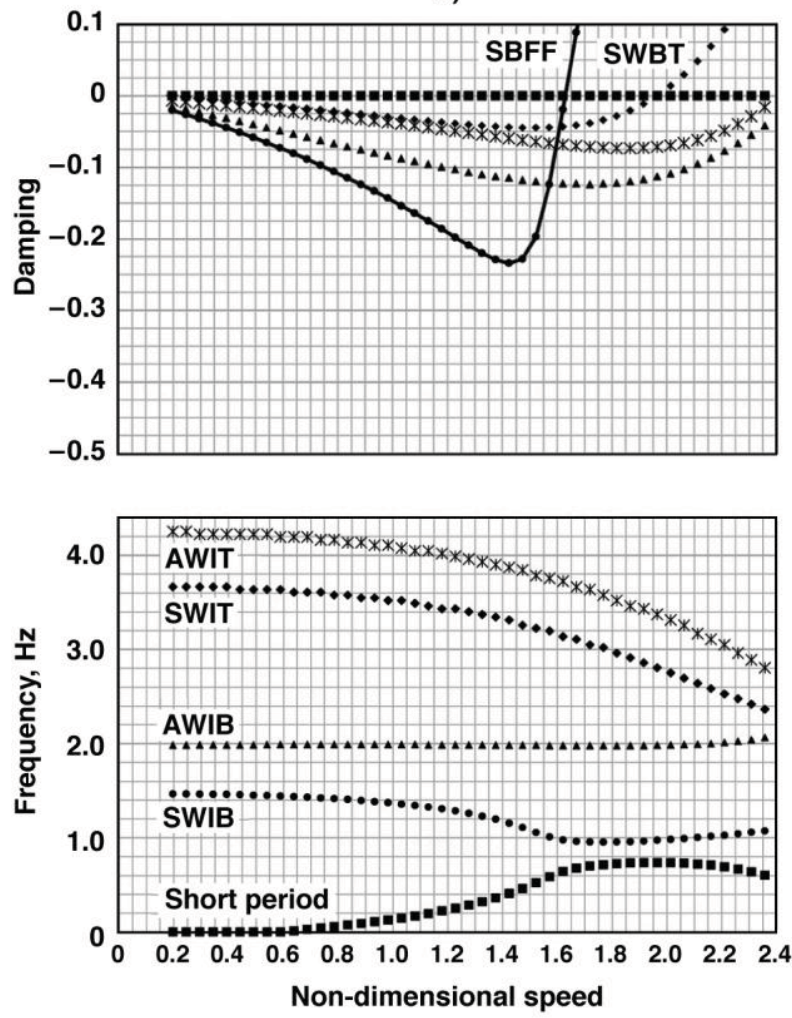

b)
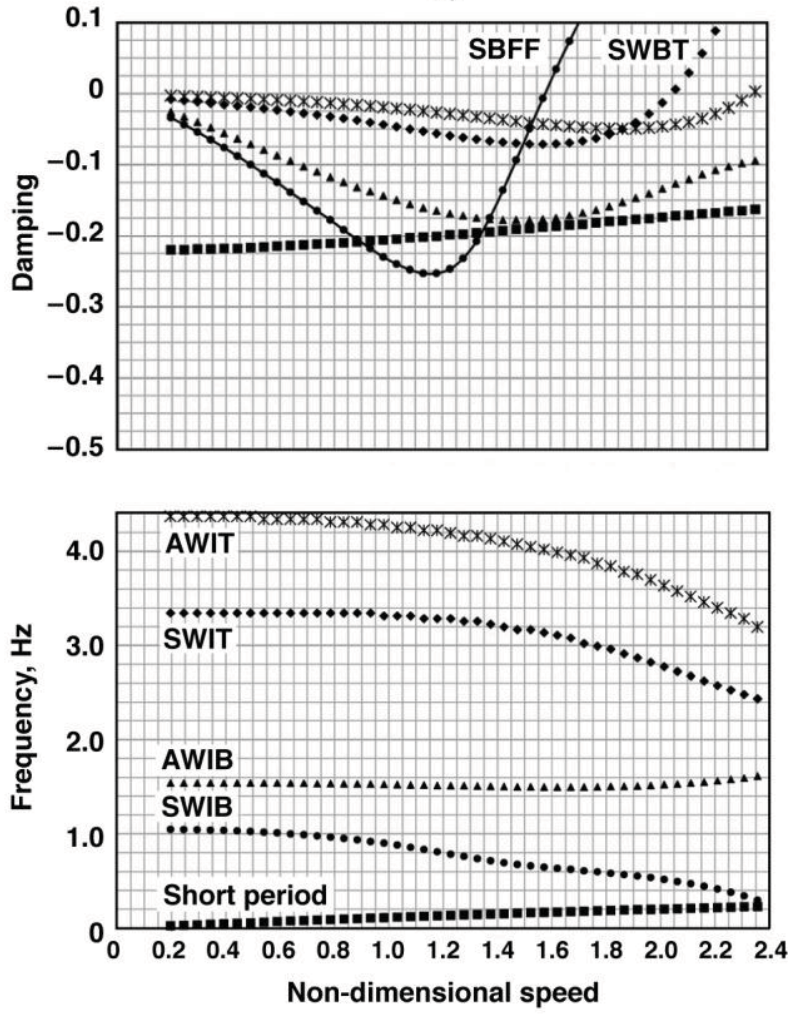

Figure 6. The V-g and V-f plots for aeroelastic tailoring optimization final design: (a) Case 1: ply thickness design variables case; (b) Case 2: ply thickness and orientation design variables case. 


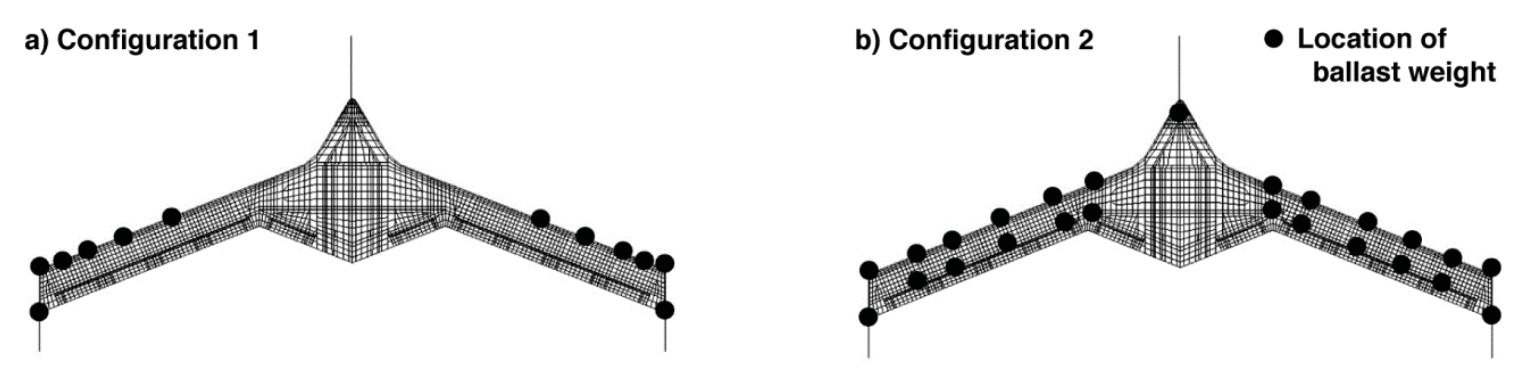

c) Configuration 3 , with a 25 -in. railing wing tip boom (five 5 -in. segments)

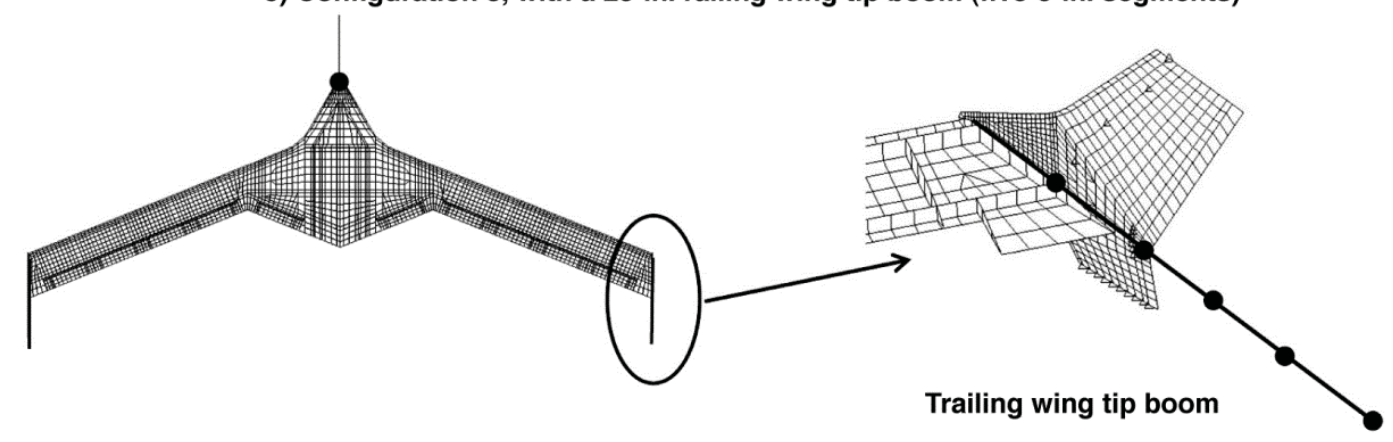

Figure 7. Flutter mass balancing optimization design configurations.

a)
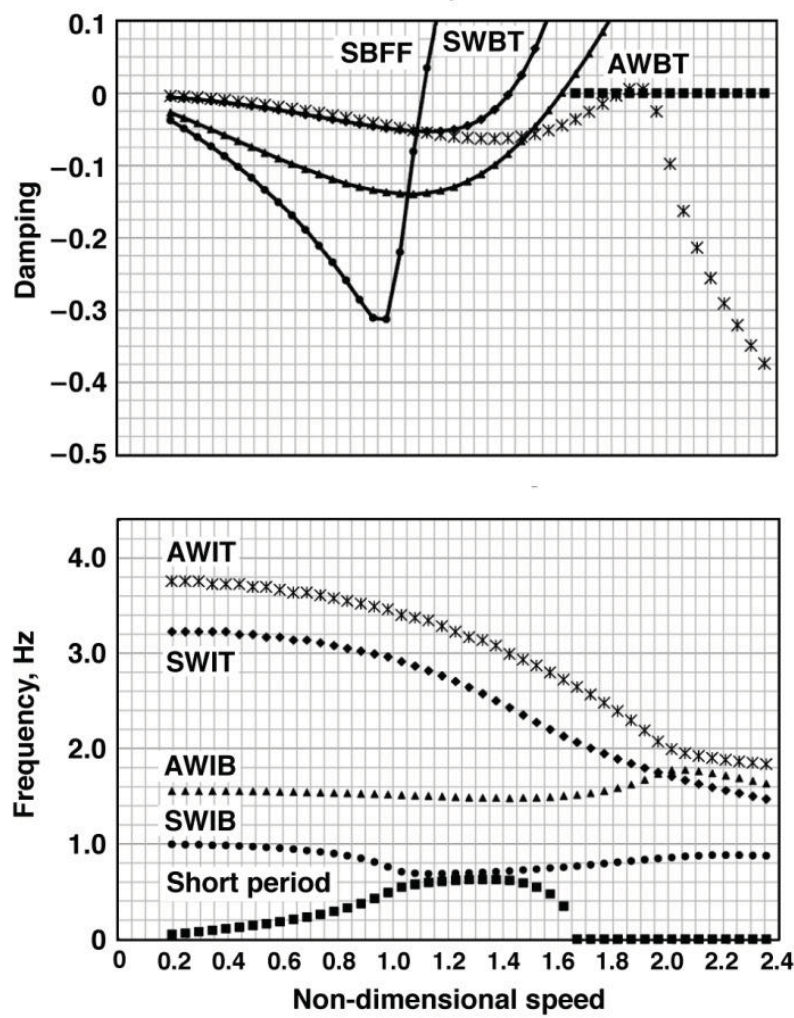

b)
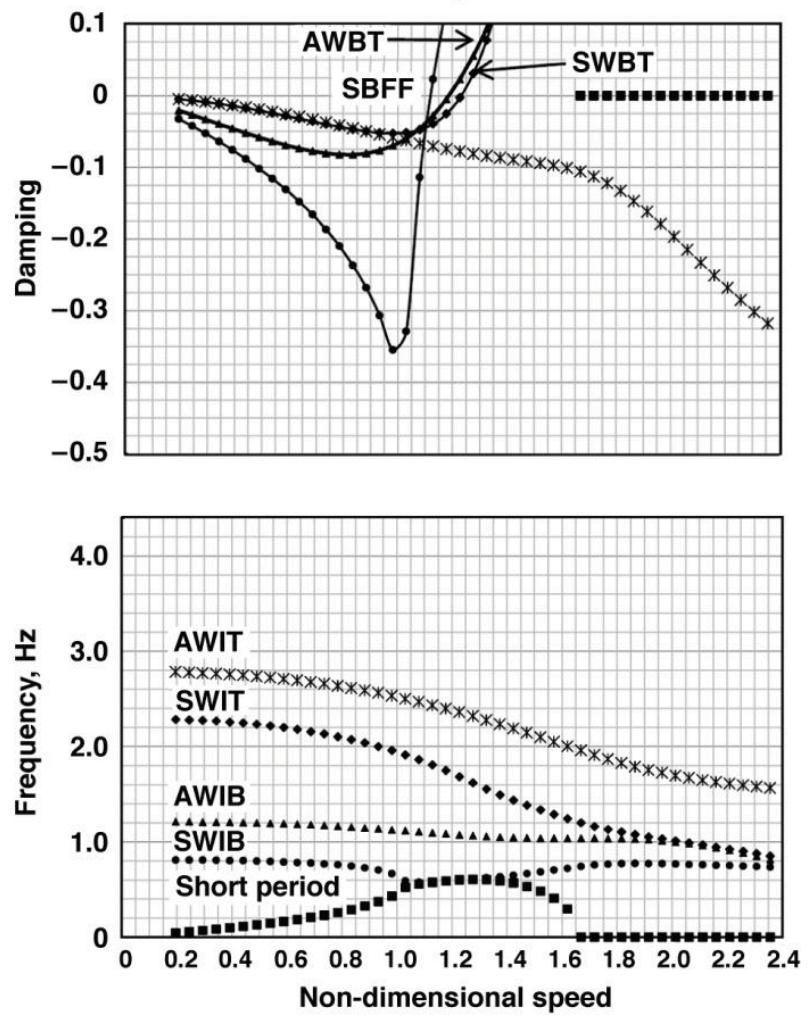

Figure 8. The V-g and V-f plots for empty fuel and empty water ballast configuration: (a) initial design; (b) final design with 20-lb nose and 4-lb trailing wing tip boom ballast. 


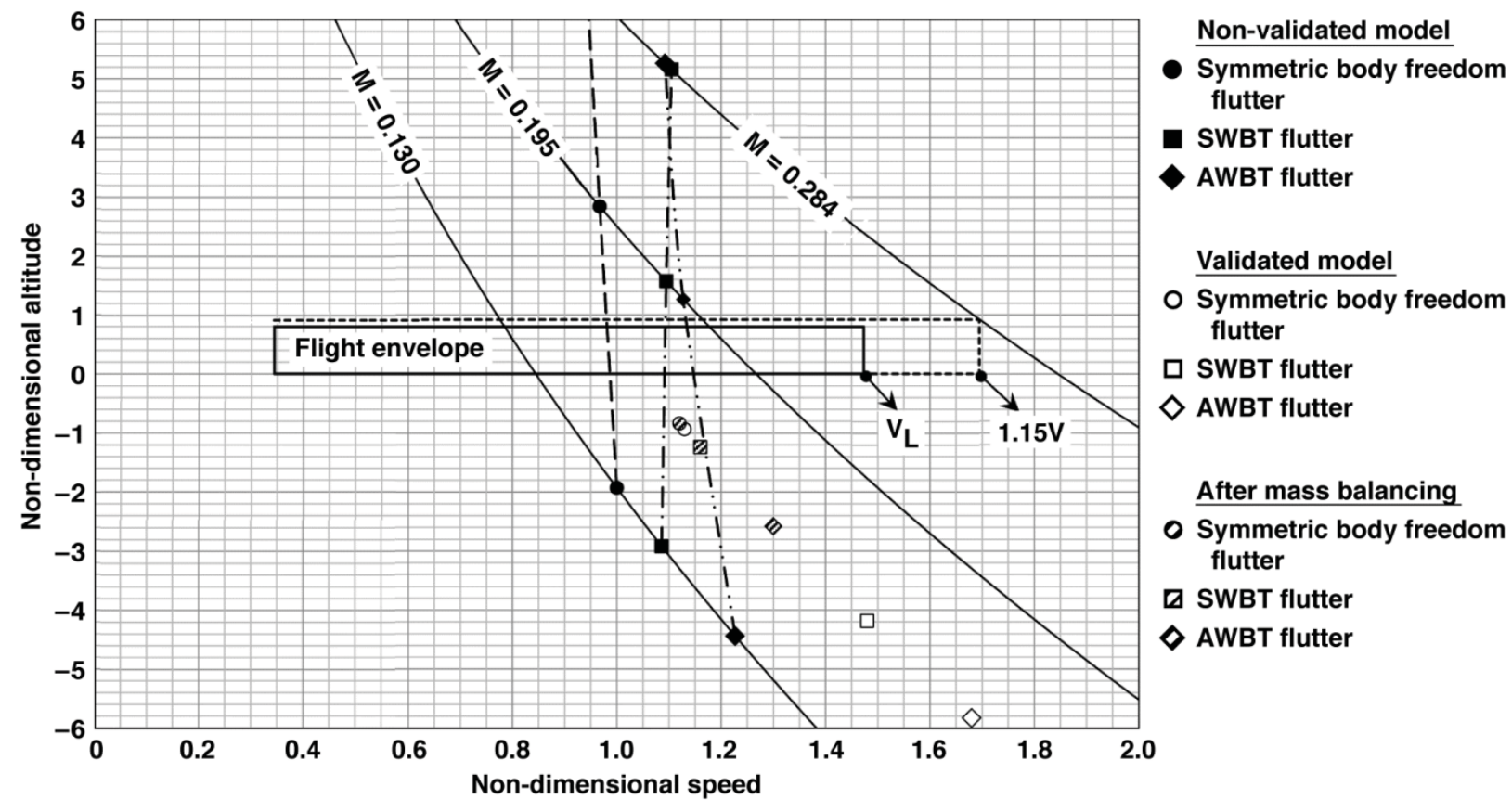

Figure 9. Non-dimensional X-56A empty fuel and empty water ballast configuration flight envelope. 


\section{References}

${ }^{1}$ Giunta, A., “A Novel Sensitivity Analysis Method for High-Fidelity Multidisciplinary Optimization of Aero-Structural Systems," AIAA-2000-0683, 2000.

${ }^{2}$ Maute, K., Nikbay, M., and Farhat, C., "Analytically Based Sensitivity Analysis and Optimization of Nonlinear Aeroelastic Systems," AIAA- 2000-4825, 2000.

${ }^{3}$ Maute, K., Nikbay, M., and Farhat, C., "Coupled Analytical Sensitivity Analysis and Optimization of Three-Dimensional Nonlinear Aero-elastic Systems," AIAA Journal of Aircraft, Vol. 39, No. 11, 2001, pp. 2051-2061.

${ }^{4}$ Pak, C.-G., and Li, W., "Multidisciplinary Design, Analysis, and Optimization Tool Development Using a Gnetic Algorithm," Proceedings of the 26th International Congress of the Aeronautical Sciences, Anchorage, Alaska, 2008.

${ }^{5}$ Pak, C.-G., "Finite Element Model Tuning Using Measured Mass Properties and Ground Vibration Test Data," ASME Journal of Vibration and Acoustics, Vol. 131, No. 1, 2009.

${ }^{6}$ Pak, C.-G. and Lung, S.-F., "Flutter Analysis of Aerostructures Test Wing with Test Validated Structural Dynamic Model," AIAA Journal of Aircraft, Vol. 48, No. 4, 2011, pp. 1263-1272.

${ }^{7}$ Pak, C.-G., "Unsteady Aerodynamic Model Tuning for Precise Flutter Prediction," AIAA Journal of Aircraft, Vol. 48, No. 6, 2011, pp. 2178-2184.

${ }^{8}$ Livne, E., "Future of Airplane Aeroelasticity," AIAA Journal of Aircraft, Vol. 40, No. 6, 2003, pp. 1066-1092.

${ }^{9}$ Sobieszczanski-Sobieski, J. and Haftka, R. T., "Multidisciplinary Aerospace Design Optimization: Survey of Recent Developments," Proceedings of the 34th AIAA Aerospace Sciences Meeting and Exhibit, Reno, Nevada, 1995.

${ }^{10}$ Weisshaar, T. A., "Aeroelastic Tailoring of Forward Swept Composite Wings," AIAA Journal of Aircraft, Vol. 18, No. 8, 1981, pp. 669-676.

${ }^{11}$ Hollowell, S. J. and Dungundji, J., "Aeroelastic Flutter and Divergence of Stiffness Coupled, Graphite/Epoxy Cantilevered Plates," AIAA Journal of Aircraft, Vol. 21, No. 1, 1984, pp. 69-76.

${ }^{12}$ Shirk, M. H., Hertz, T. J., and Weisshaar, T. A., "Aeroelastic Tailoring-Theory, Practice, and Promise," AIAA Journal of Aircraft, Vol. 23, No. 1, 1986, pp. 6-18.

${ }^{13}$ Green, J. A., "Aeroelastic Tailoring of Aft-Swept High-Aspect-Ratio Composite Wings," AIAA Journal of Aircraft, Vol. 24, No. 11, 1987, pp. 812-819.

${ }^{14}$ Vanderplaats, G. N. and Weisshaar, T. A., "Optimum Design of Composite Structures," International Journal for Numerical Methods in Engineering, Vol. 27, No. 2, 1989, pp. 437-448.

${ }^{15}$ Ringertz, U. T., "On Structural Optimization with Aeroelasticity Constraints," Structural and Multidisciplinary Optimization, Vol. 8, No. 1, 1994, pp. 16-23.

${ }^{16}$ Putnam, T. W., "X-29 Flight-Research Program,” NASA TM-86025, 1984.

${ }^{17}$ Liem, R. P., Kenway, G. K. W., Martins, J. R. R. A., "Multi-point, Multi-mission, High-fidelity Aerostructural Optimization of a Long-range Aircraft Configuration,"AIAA-2012-5706, 2012.

${ }^{18}$ ZAERO User's Manual Version 8.5, ZONA Technology, Inc., Scottsdale, Arizona, 2011.

${ }^{19}$ Charbonneau, P., and Knapp, B., A User's Guide to PIKAIA 1.0, National Center for Atmospheric Research, Boulder, Colorado, 1995.

${ }^{20}$ Erol, O. K., and Eksin, I., “A New Optimization Method: Big Bang-Big Crunch,” Advances in Engineering Software, Vol. 37, No. 2, 2006, pp. 106-111.

${ }^{21}$ DOT Design Optimization Tools User's Manual Version 5.0, Vanderplaats Research and Development, Inc., Colorado Springs, Colorado, 2001.

${ }^{22}$ MD/MSC NASTRAN 2010 Quick Reference Guide, The MacNeal-Schwendler Corporation, Santa Ana, California, 2010.

${ }^{23}$ Rodden, W. P. and Johnson, E. H., MSC/Nastran Aeroelastic Analysis User's Guide, Version 68, The MacNeal-Schwendler Corporation, Santa Ana, California, 1994.

${ }^{24}$ Beranek, J., Nicolai, L., Buonanno, M., Burnett, E., Atkinson, C., Holm-Hansen, B., and Flick, P., “Conceptual Design of a Multi-utility Aeroelastic Demonstrator,” AIAA-2010-9350, 2010. 